Review Article

\title{
Dielectric Properties of ZnO-Based Nanocomposites and Their Potential Applications
}

\author{
Daljeet Kaur $\mathbb{D D}^{1,2}$ Amardeep Bharti ${ }^{1},{ }^{3}$ Tripti Sharma $\mathbb{D}^{2},{ }^{2}$ and Charu Madhu ${ }^{1}{ }^{1}$ \\ ${ }^{1}$ University Institute of Engineering and Technology, Panjab University, Chandigarh 160014, India \\ ${ }^{2}$ Chandigarh University, Mohali, Punjab 140413, India \\ ${ }^{3}$ Elettra Sincrotrone Trieste, S.C.p.A., Basovizza 34149, Italy \\ Correspondence should be addressed to Amardeep Bharti; abharti_phy@yahoo.com and Charu Madhu; \\ charunarula81@gmail.com
}

Received 11 March 2021; Accepted 14 July 2021; Published 22 July 2021

Academic Editor: Wonho Jhe

Copyright (C) 2021 Daljeet Kaur et al. This is an open access article distributed under the Creative Commons Attribution License, which permits unrestricted use, distribution, and reproduction in any medium, provided the original work is properly cited.

\begin{abstract}
Energy storage devices constitute one of the research areas in recent years. Capacitors are commonly used for the storage of electrical energy. The current research is focusing on not only the improvement in energy density but also the materials which are environment friendly. Polymer composites are known to be technically essential materials owing to their wide range of applications. Enormous research has been devoted to zinc oxide- ( $\mathrm{ZnO}-$ ) based polymer nanocomposites, due to their extraordinary dielectric properties. This review article presents a detailed study of the dielectric properties of $\mathrm{ZnO}$-based nanocomposites. The dielectric constant study includes the effect of transition metals and rare earth metals as a dopant in $\mathrm{ZnO}$. This review gives an insight into the mechanism responsible for the variation of dielectric constant in $\mathrm{ZnO}$ nanocomposites due to various factors like size of nanoparticles, thickness of the thin film, operating frequency, doping concentration, and atomic number. The observations have been summarized to convey the mechanism and structural changes involved in the $\mathrm{ZnO}$ nanocomposites to the researchers. The deployment of biodegradable nanocomposite materials is expected to open an innovative way for their outstanding electronic applications as storage materials.
\end{abstract}

\section{Introduction}

The dielectric properties of material define its characteristic role in electronics. To study the dielectric properties of any material, dielectric constant $(k)$ is a crucial factor that determines the charge storage capability of the material [1]. High- $k$ materials are used as gate dielectrics in MOS transistors, memory cells, capacitors, supercapacitors $[2,3]$, and so forth, whereas low- $k$ materials find their applications in electrical insulation and high-speed integrated circuits [4]. The semiconductor industry is greatly influenced by dielectric materials and emerges out as a revolutionary stream of microelectronics [5]. Metal oxide dielectric materials are considered to be a key element for diverse thin-film electronic systems owing to their superior dielectric and mechanical properties [6]. Titanium dioxide $\left(\mathrm{TiO}_{2}\right)$ in rutile form exhibits a high dielectric constant and can be used as a filler in hybrid (i.e., organic-inorganic) composites for application in modern electronics $[7,8]$. Tin dioxide $\left(\mathrm{SnO}_{2}\right)$ is an n-type semiconductor possessing a wide direct bandgap of $3.37 \mathrm{eV}$ at room temperature [9]. Due to low electrical resistivity, high chemical, mechanical, and thermal stability [10], it is very useful for applications in spintronics [11], lithium-ion batteries (LIBs), and supercapacitors [12, 13]. Due to its high dielectric constant [14], $\mathrm{SnO}_{2}$ can be used for applications in thin-film electrodes, sensors, batteries, and solar cells [15].

$\mathrm{ZnO}$ is a semiconductor of groups II-VI. It is actively used due to its very attractive properties and nontoxic nature. Among metal oxides, nanostructured zinc oxide $(\mathrm{ZnO})$ exhibits exceptional electronic, optical, and electrochemical properties. In addition to this, the wide bandgap $(3.37 \mathrm{eV})$ and massive exciton binding energy $(60 \mathrm{meV})$ permit the material to operate at much higher voltage, frequency, and 
temperature than conventional semiconductors [16]. Moreover, $\mathrm{ZnO}$-based composites have shown up potential applications in the field of industrial electronic devices like transducers, electrochemical sensors, solar cells, supercapacitors, and lithium-ion batteries [17-19]. $\mathrm{ZnO}$ is the most widely used inorganic compound because of its unique electronic, physical, and chemical properties [20]. This review article deals with the fundamental aspects behind the dielectrics along with the effective role of particle size and metal doping in $\mathrm{ZnO}$ to study its dielectric behaviour. Furthermore, the relative effect of transition metal and rareearth-metal are also discussed in detail towards the dielectric origin in $\mathrm{ZnO}$. Lastly, $\mathrm{ZnO}$ doped biodegradable polymer nanocomposites and their applications have been discussed thoroughly in this study.

\section{Dielectric Materials}

Dielectric materials are insulating materials. However, dielectric materials have some additional properties as compared to insulators. As they do not allow the flow of charge through them, they permit exerting electrostatic field and hence storing charge [21]. The thin films made up of dielectric materials extend enormous applications in the electronic industry like barrier layers, gate oxide, varactor dielectrics, and electrical isolation between conductive regions [22]. Numerous transition metal oxides demonstrate colossal dielectric constant and therefore have enormous potential for applications in modern microelectronics for the development of new capacitors for energy storage [23]. Lunkenheimer et al. observed a larger dielectric constant in various transition metal oxide materials, for example, $\mathrm{CaCu}_{3} \mathrm{Ti}_{4} \mathrm{O}_{12}$ has a $k$ value of 17000 and $\mathrm{La}_{2} \mathrm{SrNiO}_{4}$ has a $k$ value of 10000 for their application in capacitive circuits [23]. Meher et al. suggested that $\mathrm{Sr}_{2} \mathrm{TiMnO}_{6}$ can be used as dielectric material in capacitors, due to its large dielectric constant of the order of $10^{5}$ [24]. The value of $k$ is larger due to the high degree of polarization.

2.1. Polarization. When an atom is subjected to an electric field, it gives rise to the formation of a dipole [25]. If the dielectric material is subjected to an alternating field by placing it between two conducting plates acting as electrodes, it gives rise to the formation of a capacitor $[26,27]$ as shown in Figure 1. According to the equation of the capacitor,

$$
C=\frac{\left(\varepsilon_{0} \varepsilon_{r} A\right)}{d}
$$

Capacitance $(C)$ depends upon four factors: area of the electrodes $A$, spacing between the electrodes $d$, permittivity of free space $\varepsilon_{0}=8.854 \times 10^{-14} \mathrm{~F} / \mathrm{cm}$, and relative permittivity or dielectric constant of the material $\varepsilon_{r}$.

All the dipoles within the dielectric material get aligned in the same direction as those of the applied electric field. The alignment of dipoles gives rise to an induced electric field which is in a reverse direction to the applied electric field

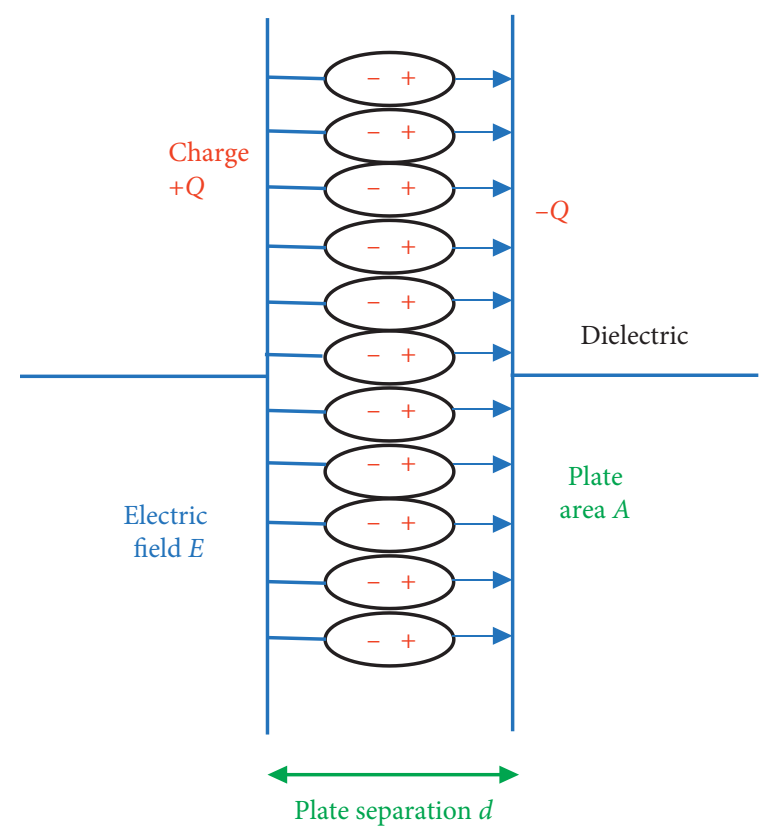

FIgURE 1: Structure of the dielectric capacitor.

$[28,29]$. This process of alignment of dipoles is called polarization, due to which the material can store charge in it [30].

2.2. Source of Polarization. There are several aspects that give rise to polarization in the materials. Polarization is responsible for the relative permittivity of a material, subjected to an electric field [31]. It is originated from four different roots, namely, electronic, ionic, orientation, and interfacial polarization. Polarization is a frequency-dependent phenomenon [25, 32] as shown in Figure 2.

In a material, there may be single or multiple polarization sources active at a time. In a material having high relative permittivity, a greater number of sources or all these sources are active [31]. On the other hand, a few will be active in a material having low relative permittivity. In $\mathrm{ZnO}$, all the four types of polarizations exist but the active one is dependent on the frequency of operation [33-37] The origin of high $k$ in a material at low frequencies is the presence of all four sources of polarization, and it starts decreasing with the increase in frequency since dipoles in the material cannot follow the high frequency of applied field [38]. The value of $k$ in a material increases with the increase in temperature which is attributed to the fact that a greater number of frozen dipoles are liberated due to thermal energy [39].

2.3. Dielectric Constant and Dielectric Loss. The ratio of absolute permittivity $(\varepsilon)$ of the material and permittivity of free space $\left(\varepsilon_{0}\right)$ is called relative permittivity $\left(\varepsilon_{r}\right)$ or dielectric constant $(k)$, which is represented as follows:

$$
\varepsilon_{r}=\frac{\varepsilon}{\varepsilon_{0}} \text {. }
$$

When a thick film of dielectric material is subjected to AC voltage, depending upon $\varepsilon_{r}$ of the material, it permits or 


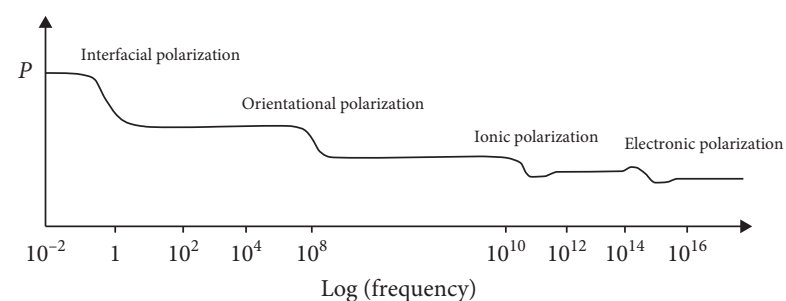

Figure 2: Frequency dependence of different dielectric polarizations.

allows the electric lines of force to get absorbed in it and gives rise to electric charge storage phenomena. The electric energy that does not get absorbed in the material and is dissipated in the form of heat is called dielectric loss. The complex permittivity of a material, which is subjected to an alternating field, is defined by the Debye expression [40-42]:

$$
\varepsilon^{*}(\omega)=\varepsilon_{\infty}+\left(\frac{\varepsilon_{s}-\varepsilon_{\infty}}{1+J \omega \tau}\right),
$$

where $\varepsilon_{\infty}=$ dielectric constant at high frequency, $\varepsilon_{s}=$ dielectric constant at low frequency, $\omega=2 \pi f, \tau=$ relaxation time, and $\varepsilon^{*}(\omega)$ is complex permittivity and is given by

$$
\varepsilon^{*}=\varepsilon^{\prime}-J \varepsilon^{\prime \prime},
$$

where $\varepsilon^{\prime}=$ real part of permittivity and is given by

$$
\varepsilon^{\prime}=\varepsilon_{\infty}+\left(\frac{\varepsilon_{s}-\varepsilon_{\infty}}{1+\omega^{2} \tau^{2}}\right)
$$

which is also called the real part of the complex dielectric constant $(k) \cdot \varepsilon^{\prime \prime}=$ imaginary part of permittivity and is given by

$$
\varepsilon^{\prime \prime}=\left(\frac{\left(\varepsilon_{s}-\varepsilon_{\infty}\right) \omega \tau}{1+\omega^{2} \tau^{2}}\right),
$$

which is also called the imaginary part of the complex dielectric constant $(k) . \varepsilon^{\prime}$ and $\varepsilon^{\prime \prime}$ both are frequencydependent.

The dielectric loss factor is given by

$$
\tan \delta=\frac{\varepsilon^{\prime \prime}}{\mathcal{E}^{\prime}} .
$$

Metal oxides possess a high dielectric constant along with low dielectric loss, thus having huge potential to be used in microelectronics industry $[22,23]$.

\section{Classification of Dielectric Materials}

The dielectric constant $(k)$ of a material is basically the charge storage capability of that material. Materials can be classified into two categories: high- $k$ materials and low- $k$ materials [5]. Materials that have a value of dielectric constant more than silicon nitride, $k>7$, are called high- $k$ materials and the materials that have a dielectric constant value less than silicon dioxide, $k<3.9$, are called low- $k$ materials. The lowest value of $k$ is of air, which is equal to unity. And the highest value of $k$ is of relaxor ferroelectric, which is $\sim 24000$ at $1 \mathrm{KHz}$ [4].

3.1. Applications of High- $k$ and Low- $k$ Materials. High- $k$ materials can be used to develop efficient memory cells for high storage memory chips [43], to develop passive components like capacitors and supercapacitors [44]. They can be used for gate dielectrics in MOS transistors and TFTs [45]. Low- $k$ materials find their applications in EMI Shielding [46], in the field of satellite communication, telecommunication in space [35], and high-speed IC packaging [47].

3.2. Demand for High-k Materials. Nowadays, electronic gadgets have become the fundamental need of daily life and with continuous thought of green evolution to minimize the use of paper, an efficient memory storage device plays a significant role [48]. These memory chips are made up of small capacitors and transistors as supporting circuitry [4]. The continuous efforts in the research and development in the field of material science make it possible to decrease the size of transistors and to accommodate a larger array on a single chip resulting in enhanced performance and storage. From equation (1), there are three approaches through which the storage capacity of a capacitor can be improved. First, the capacitance can be increased by increasing the area $A$, of capacitor's plates, but it will increase the device size also, which is not acceptable [26]. The second is to decrease the thickness of dielectric $d$ or gap between capacitor's plates [27]. But dielectric breakdown strength of a material imparts constrain over a certain limit on the dielectric thickness, beyond that the material will either breakdown or the leakage current will start to flow through it. Therefore, the only possibility to enhance the performance and storage capacity of transistors/capacitors is to increase the value of the dielectric constant or to use a high- $k$ material [28].

Thin-film transistors (TFTs) are the basic building block of every electronic gadget. TFTs are used in almost every flat panel display as a switch to drive the pixels. The resolution and clarity of the display depend upon the switching speed and performance of the TFTs [49-51]. The performance of a TFT is greatly influenced by the properties of its dielectric layer. The dielectric layer is responsible for the accumulation of charge in the channel and leakage current in the device $[52,53]$. There is a fundamental limitation on the thickness of a silicon-based gate dielectric that the oxides having a thickness less than $2 \mathrm{~nm}$ suffer from direct tunnelling current or leakage current [54]. Therefore, high- $k$ materials are required to overcome this problem. Due to these reasons, high- $k$ materials are high in demand in the electronic industry and gain the attention of researchers [27]. Several materials like $\mathrm{Ta}_{2} \mathrm{O}_{5}, \mathrm{Nb}_{2} \mathrm{O}_{5}, \mathrm{Y}_{2} \mathrm{O}_{3}, \mathrm{TiO}_{2}, \mathrm{Al}_{2} \mathrm{O}_{3}, \mathrm{HfO}_{2}$, and $\mathrm{ZrO}_{2}$ are available which have a value of dielectric constant varying from 10 to $100[22,55]$. Water $\left(\mathrm{H}_{2} \mathrm{O}\right)$ has $k=80$ but it has very low dielectric strength. It cannot withstand high voltage. Hence, it cannot be used for practical applications [56]. So, there is a need to search new materials or synthesize new materials and tailor their properties as required. $\mathrm{ZnO}$ is one of the materials which is nontoxic and is safe for the 
environment. It can offer greater dielectric constant after doping it with some other metals; hence, it can satisfy the need of energy storage devices.

\section{Factors Affecting the Value of Dielectric Constant of a Material}

Apart from frequency and temperature dependence, $k$ of a material is also affected by its structural properties or microstructure:

(1) Crystallite size: if the size of the crystal of a material is large, then the value of $k$ is also high. This is because a larger particle contains a greater number of dipoles which get aligned under the influence of the electric field and results in greater permittivity, thus a higher value of $k[57,58]$.

(2) Porosity: if the material is porous or has low density, then the value of $k$ will be low [59]. A porous material is a dense material which is filled with random air pores. The value of permittivity or $k$ of the material will decrease because the relative permittivity of air is much lower than the material itself; hence, with the increase in porosity, the overall value of $k$ decreases [60].

(3) Composition and doping concentration: the composite materials consist of more than one material having different values of $k$. So, the resulting dielectric constant of the composite material will depend upon all the constituents. A dopant of low $k$ will reduce the overall effective value of $k$ of the composite material depending upon its percentage of concentration. A higher concentration of low- $k$ dopant will result in more dip in the overall effective value of $k$ of the material as compared to the lower concentration of dopant [61, 62].

(4) Defects: above room temperature, every material fundamentally has point defects to establish thermal equilibrium in the system:

(a) Surface defects: the surface of every material possesses inherent defects as it has a smaller number of bonds than the atoms in the bulk portion of the material. These loose bonds of the surface are called dangling bonds. If a material has more numbers of dangling bonds, that means it has a good density of charge carriers that will lead to large polarization [63].

(b) Vacancies: they exist in the system when there are some missing atoms in the crystal called vacancies. The existence of vacancies has a direct impact on the dielectric constant of the material [64]. The presence of vacancies in a material helps in trapping the charge carriers which generates large polarization, hence resulting in a high dielectric constant at low frequencies [65].

(c) Substitution defects: when some impurity atom or doping atom substitutes in the place of a host atom, it gives rise to substitution defects. These defects trap the charge carriers and produce large polarization, hence increasing the value of the dielectric constant at low frequencies [66].

(d) Grain boundaries: grain boundary is an interface that separates two grains in a polycrystalline material. It arises due to inhomogeneity in the surface of the material. If a material has a greater number of grain boundaries, then the value of $k$ becomes high in the range of frequency, where interfacial polarization is active, as grain boundaries trap the charge carriers at the interfaces and do not allow them to move. Hence, they enhance the polarization and ultimately give rise to an increased value of dielectric constant at low frequencies [67].

\section{Zinc Oxide (ZnO)}

Zinc oxide $(\mathrm{ZnO})$ is an $\mathrm{n}$-type semiconductor that belongs to the II-VI group of the periodic table. It has been extensively studied and analysed by numerous researchers due to its outstanding properties, which include cost-effectiveness, wide availability, and nontoxic nature [68-70]. ZnO exhibits a wide bandgap of $3.37 \mathrm{eV}$. It also possesses a high exciton binding energy of $60 \mathrm{meV}$, which permits the device to operate at much higher voltage, frequency, and temperature than conventional semiconductors [71]. It shows a great performance of photocatalytic activities for the degradation of organic pollutants present in water, due to its ability to absorb almost the entire UV spectrum [72-74]. ZnO exhibits high quantum efficiency due to greater order of electron mobility $200-300 \mathrm{~cm}^{2} \cdot \mathrm{V}^{-1} \cdot \mathrm{s}^{-1}$ [75-77]. It has already been discussed that the dielectric properties of a material depend upon its structure. $\mathrm{ZnO}$ has structural defects like oxygen vacancies and zinc interstitials which are intrinsic to the synthesis process [66]. Huang et al. demonstrated that the number of oxygen vacancies that exist in the $\mathrm{ZnO}$ lattice exhibit a great impact on the relative permittivity and hence its dielectric properties [64]. $\mathrm{ZnO}$ is a polar molecule, hence possessing a permanent dipole moment, due to whichthe electronic polarization is high at low frequencies and decreases as the frequency of the applied field is increased [78]. Due to exceptional properties like great thermal stability, antimicrobial features, and biocompatibility, $\mathrm{ZnO}$ has proved to be a promising antibacterial agent [79-82]. $\mathrm{ZnO}$ in the food packaging industry has proved to improve the shelf life of food. It shows superb antibacterial properties for almost the entire range of bacteria including Staphylococcus aureus and Escherichia coli which is responsible for spoiling the food [83-86]. Due to the nontoxic nature of $\mathrm{ZnO}$ nanoparticles, these are biocompatible and hence safe for human beings [87-89].

Along with all these properties, it is ecofriendly, cheap, and widely available [90-92]. $\mathrm{ZnO}$ finds its application in drug delivery [93], targeted gene delivery, and tumour imaging [94]. It is used as an additive in ointments for various skin problems [95], as an antiseptic [96]. In the textile industry for developing a fabric which is UV radiation protected due to its UV absorption properties [97]. For food 
packaging application, its antimicrobial properties help it to prevent the growth of bacteria which spoils the food and thus develop diseases $[98,99]$. It also finds applications in devices like LED [100-104], TFTs [105, 106], memory cells [107], solar cells [108], photocatalyst [109], gas sensors [110], lasers [111], storage devices [112], and photodetectors [113].

\subsection{Dielectric Constant of Bulk $\mathrm{ZnO}$ and $\mathrm{ZnO}$ Nanoparticles.} The value of $k$ of any material is a very important characteristic for various electronic applications like capacitors, transistors, dry electrodes, memory cells, passive components, and gate dielectrics. The $k$ value for bulk $\mathrm{ZnO}$ ranges from 6 to 10 approximately at $1 \mathrm{MHz}$ frequency and at room temperature [114]. Dielectric properties of $\mathrm{ZnO}$ have been examined by various researchers to find out the value of $k$ of pure $\mathrm{ZnO}$. Look et al. [115] found the value of the dielectric constant of bulk $\mathrm{ZnO}$ to be $\approx 8$ at $1 \mathrm{MHz}$ and at room temperature. Langton and Matthews [116] performed the dielectric studies of pure $\mathrm{ZnO}$ in the frequency range of $50 \mathrm{KHz}$ to $25 \mathrm{MHz}$ at $25^{\circ} \mathrm{C}$ and found the value of $k$ for $\mathrm{ZnO}$ is 10.4 in the frequency range of $1 \mathrm{MHz}$ to $10 \mathrm{MHz}$. As the frequency is increased above $10 \mathrm{MHz}$ the value of $k$ decreases and becomes 9.1 at $25 \mathrm{MHz}$.

It is well known that, with the increase in the $\mathrm{ZnO}$ layer thickness, the value of $k$ increases at room temperature. At a fixed frequency, the $k$ of $\mathrm{ZnO}$ varies with the variation of its thickness and temperature of operation [105]. It has been observed by Shashikant Sharma et al. that the dielectric constant increases with the increase in the film thickness of $\mathrm{ZnO}$ thin films, due to the quantum confinement effect [117]. The reduction in the value of dielectric constant of the thinner film is attributed to the powerful captivity of the smaller $\mathrm{ZnO}$ grains [118]. Table 1 and Figure 3 show the variation of dielectric constant as a function of the thickness of $\mathrm{ZnO}$ thin films at a fixed wavelength of $600 \mathrm{~nm}$. The grade of crystallinity of $\mathrm{ZnO}$ thin films refines with the increase in thickness of films. With the increase in thickness of deposited films, the disorders like dislocation density, stress, and strain reduces. The dielectric behaviour of $\mathrm{ZnO}$ is ascribed to the defects like oxygen vacancies along with zinc interstitials [78]. In the optical properties, blue shift is observed with the decrease in thickness [119].

Lanje et al. [33] studied the dielectric properties of $\mathrm{ZnO}$ nanoparticles at room temperature and found the value of $k$ to be 10.26 at $1 \mathrm{MHz}$. Literature disclosed that the value of $k$ of a synthesized material depends upon various factors. The first factor is the size of nanoparticles of the synthesized material. Size dependence of the dielectric constant of $\mathrm{ZnO}$ nanoparticles has been studied in this paper. As shown in Table 2 and Figure 4, an increase in the value of $k$ is observed with the increasing size of nanoparticles. It has been observed that the larger is the crystallite size of the particle, the higher is the value of $k$ because the larger particle contains a greater number of dipoles which get aligned under the influence of the electric field, hence resulting in greater permittivity and higher value of $k$ [57].

The dielectric constant of bulk zinc oxide is observed to be less than $\mathrm{ZnO}$ nanoparticles due to the fact that
TABLE 1: Variation of the dielectric constant of $\mathrm{ZnO}$ thin films with the variation of film thickness at a fixed wavelength of $600 \mathrm{~nm}$ [118].

\begin{tabular}{lc}
\hline Thickness of the ZnO thin film (nm) & Value of dielectric constant \\
\hline 190 & 3.5 \\
222 & 4.5 \\
250 & 5 \\
342 & 6 \\
\hline
\end{tabular}

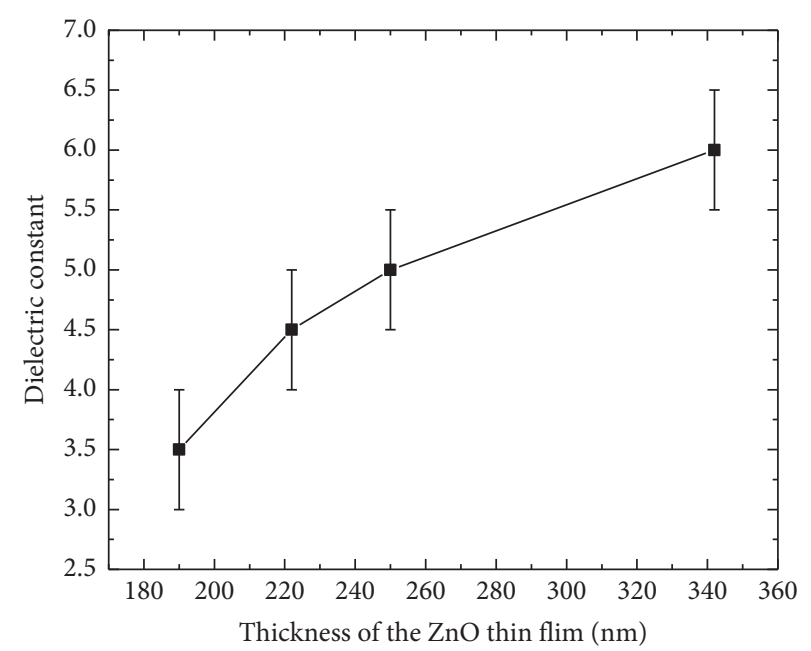

Figure 3: Variation of the dielectric constant of $\mathrm{ZnO}$ thin films with respect to film thickness.

TABLE 2: Variation of dielectric constant of $\mathrm{ZnO}$ nanoparticles with respect to the particle size.

\begin{tabular}{lcc}
\hline Crystallite size of pure $\mathrm{ZnO}$ & Dielectric constant & References \\
\hline 15 & 5 & {$[65]$} \\
19 & 14.78 & {$[120]$} \\
19.97 & 9.7 & {$[78]$} \\
22.84 & 18.5 & {$[121]$} \\
33.03 & 17 & {$[122]$} \\
55 & 45 & {$[123]$} \\
\hline
\end{tabular}

semiconductor nanoparticles exhibit a quantum confinement effect. As an outcome of their size in the nanometric range, the widening of the bandgap is caused when the spatial dimension is reduced. Quantum confinement regulates the band structure of the nanoparticles; hence, dielectric properties also change as the size of the nanoparticles is changed [124].

Pure $\mathrm{ZnO}$ has limited electronic and optical applications as pure $\mathrm{ZnO}$ has blue light emission which is the least eye sensitive colour and shows more scattering [125]. Pure ZnO has fixed and specific electric properties like bandgap, electron mobility, thermal conductivity, and exciton binding energy. The bandgap of $\mathrm{ZnO}$ can be tuned to a high or low value by adding some dopant. The addition of magnesium $(\mathrm{Mg})$ into $\mathrm{ZnO}$ will increase the bandgap from $3.37 \mathrm{eV}$ to $4 \mathrm{eV}$ and the addition of cadmium (Cd) will decrease the bandgap to $3 \mathrm{eV}$ [36]. Electrical and dielectric properties of $\mathrm{ZnO}$ depend upon the concentration of dopant. So, these 


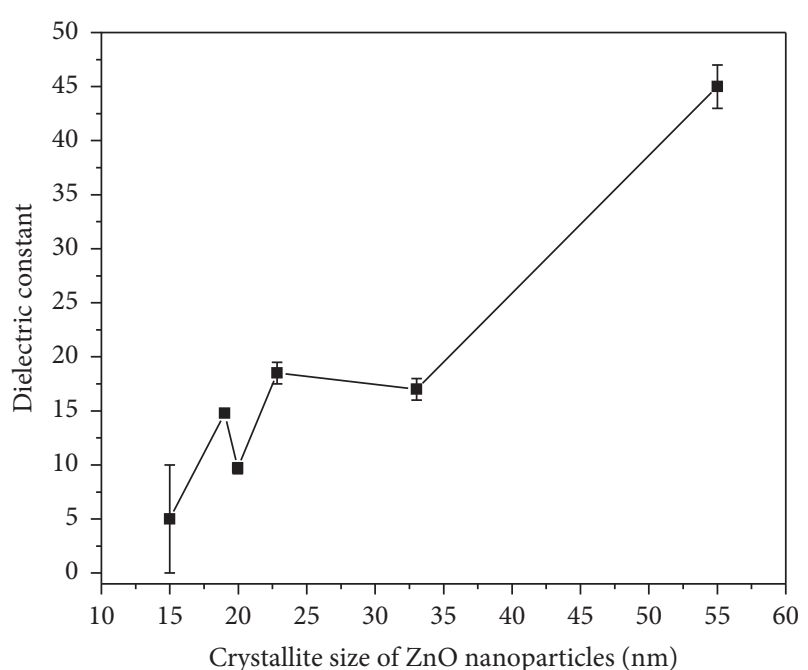

FIGURE 4: Variation of the dielectric constant of $\mathrm{ZnO}$ nanoparticles with respect to the crystallite size of $\mathrm{ZnO}$ nanoparticles.

properties can be tailored by adding some other materials in it and creating the composite.

\section{Composites}

When two or more materials which have quite different physical and chemical characteristics are combined in a manner that their properties remain distinct at the microscopic level, this type of material is called a composite material. Due to good physical strength and high melting point, high thermal conductivity composites find their applications in various industries [39].

6.1. Metal-Doped $\mathrm{ZnO}$ Nanocomposites and Their Applications. Two groups of metals, transition metal and rare earth metal, doped $\mathrm{ZnO}$ nanoparticles have been chosen for this review article. Ferromagnetism in transition metal (TM) doped $\mathrm{ZnO}$ is theoretically investigated by Sato and Katayama-Yoshida [126]. It turned out that most of the incomplete $3 \mathrm{~d}$ shell metal ions can be used to produce room-temperature magnetism in $\mathrm{ZnO}$, doped with transition metal [127]. In the case of rare earth (RE) doping, the $4 \mathrm{f}$ shell electrons are localized, exchange interactions are indirect as they occur via the $5 \mathrm{~d}$ or 6 s conduction electrons. However, the high orbital momentum leads to a high total magnetic moment per atom [128]. Other than introducing ferromagnetism transition metals, rare earth metal ions have been used by many researchers to dope $\mathrm{ZnO}$. The doping thus modifies its optical, electrical, and dielectric properties by changing the bandgap and electronic structure of the composite material. Due to enhanced properties, it turned perfect for different technological applications like LED, TFTs, memory cells, solar cells, photocatalyst, gas sensors, lasing, storage devices, and photodetectors $[129,130]$. Various researchers have synthesized different composites and have checked their dielectric properties.
6.1.1. Transition Metal-Doped $\mathrm{ZnO}$. In this article transition metal-, Cr [121], Mn [57], Fe [78], Co [131, 132], Ni [122], and $\mathrm{Cu}$ [123], doped $\mathrm{ZnO}$ nanoparticles have been discussed for their dielectric studies. There are various factors that affect the value of the dielectric constant of a material like operating frequency, percentage of doping concentration, and atomic number of the dopant metal.

The first factor is the operating frequency: at low frequency, the value of $k$ is high, and at high frequencies, the value becomes low for every material due to polarization phenomena [41, 133]. Figure 5 shows the graph which shows the variation of the dielectric constant of various transition metal-doped $\mathrm{ZnO}$ nanoparticles with respect to frequency in the range of $0 \mathrm{~Hz}$ to $10 \mathrm{MHz}$. Figure 5 shows that the value of the dielectric constant of every metal-doped $\mathrm{ZnO}$ is high at low frequencies since all four sources of polarization are active at low frequencies. $\mathrm{ZnO}$ is a polar molecule, so all the dipoles get aligned in the direction of the applied electric field and give rise to a higher value of $k$. As the frequency increases the value of $k$ starts decreasing and becomes constant at a higher frequency because the dipoles are unable to align themselves with the changing direction of the applied field. Hence, the value of $k$ decreases at high frequencies [120-123]. The phenomena of dielectric dispersion in such heterogeneous structures can be simply explained by the Maxwell-Wagner model [134-136]. According to this model, a dielectric medium is composed of conducting grains which are separated by resistive grain boundaries. The grains are effective at high frequencies and the grain boundaries are effective at low frequencies. Under the influence of the external field, the charge carriers easily transfer through grains but get trapped into the grain boundaries at low frequencies; this produces large polarization and high $k$. Among all the transition metals discussed in this article, $\mathrm{Mn}$ is showing a significant dielectric dispersion. The higher value of $k$ at low frequencies can be explained based on interfacial polarization due to inhomogeneous structure, defects like oxygen vacancies, and grain boundary defects. Due to this reason, the value of $k$ in $\mathrm{Mn}$-doped $\mathrm{ZnO}$ is quite high at low frequencies; as the frequency increases, the value of $k$ starts decreasing; and after a particular frequency, it becomes constant due to the fact that hopping between metal ions cannot follow the alternating field and are unable to align themselves in the direction of the electric field.

(1) Effect of Transition Metal Doping Concentration on Dielectric Constant. The second factor that affects the value of $k$ is the composition and doping concentration. When $\mathrm{ZnO}$ nanoparticles are doped with metal ions, the crystal structure and microstructure of the nanoparticles change drastically which affects its chemical, electrical, mechanical, optical, and dielectric properties. This gives rise to various applications. The variations of the dielectric constant of different transition metal-doped $\mathrm{ZnO}$ nanoparticles have been discussed with respect to the percentage of doping concentration. As shown in Figure 6, some of the doped materials have a linearly decreasing trend with the increase in doping percentage and others have an increasing trend. 


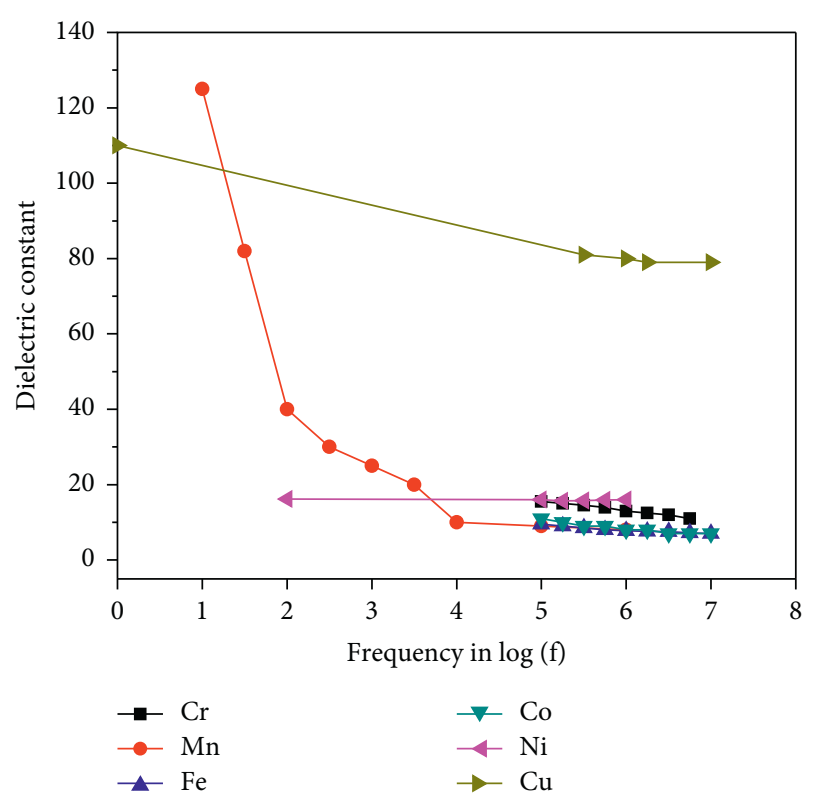

FIgURE 5: Variation of the dielectric constant of various transition metal-doped $\mathrm{ZnO}$ nanoparticles with respect to frequency.

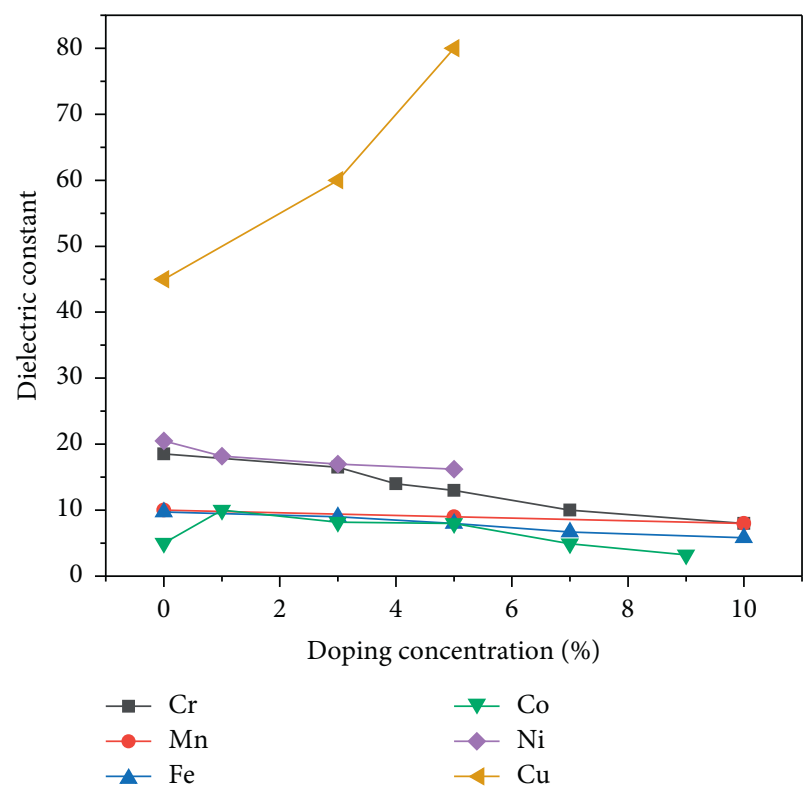

FIGURE 6: Variation of dielectric constant of transition metal-doped $\mathrm{ZnO}$ nanoparticles with respect to doping concentration at $1 \mathrm{MHz}$ frequency.

Figure 6 shows the variation of $k$ of transition metaldoped $\mathrm{ZnO}$ nanoparticles with different doping concentrations at $1 \mathrm{MHz}$ frequency. The value of $k$ decreases with the increase in the concentration of $\mathrm{Cr}, \mathrm{Mn}, \mathrm{Fe}, \mathrm{Co}$ [132], and $\mathrm{Ni}$ into the $\mathrm{ZnO}$ nanoparticles. The doping of these metals prevents the growth of crystal grains and slows down the motion of a grain boundary. This reduction in motion of grain boundaries can be well explained with the Zener pinning effect [122]. As the ionic radius of these metals is smaller than $\mathrm{Zn}$, it reduces the lattice parameters and crystallite size of the doped material $[137,138]$. It has already been discussed that, with the reduction in crystallite size of nanoparticles the value of $k$ decreases [57, 58]. Hence, a reduction in the size of nanoparticles leads to a reduction in the $k$ value of doped material. When these metal ions are doped into $\mathrm{ZnO}$ at a lower concentration, the hopping mechanism between the metal ion and $\mathrm{Zn}^{2+}$ is predominant which results in a higher value of $k$. As the concentration is increased the metal ion in $\mathrm{ZnO}$ acts as a deep donor and decreases the concentration of intrinsic donors. It substitutes $\mathrm{Zn}^{2+}$ ions and produces charge imbalance around the dopants, which reduces the value of $k$. But in case of $\mathrm{Cu}$, the value of $k$ increases with the increase in the doping concentration; this is due to the abundance in electron exchange between $\mathrm{Zn}$ and $\mathrm{Cu}$ ions at all frequencies. Furthermore, it is seen that doping with $\mathrm{Cu}$ ions increases the grain size of doped material, so a large value of the dielectric constant may be attributed to the larger grain size and oxygen vacancies. Hence, it can be concluded that $\mathrm{Cu}$ doping enhances the polarization of $\mathrm{ZnO}$ nanoparticles.

(2) Effect of Atomic Number of Transition Metal on Dielectric Constant. The third factor is the atomic number of the dopant material. In order to compare the relative behaviour of various transition metal-doped $\mathrm{ZnO}$ nanocomposites, we have selected fixed doping concentration of $5 \%$ and fixed frequency of $1 \mathrm{MHz}$ for every metal-doped $\mathrm{ZnO}$ nanocomposite. Figure 7 shows the variation of $k$ value of various transition metal-doped $\mathrm{ZnO}$ nanoparticles at 5\% doping and at $1 \mathrm{MHz}$ frequency with respect to their atomic number. It has been observed that the value of $k$ of various transition metal-doped $\mathrm{ZnO}$ nanoparticles increases exponentially as the atomic number increases from 24 to 29. The exceptional increase in the dielectric constant of $\mathrm{Cu}$ doped $\mathrm{ZnO}$ nanoparticles is due to the anomalous electronic configuration of $\mathrm{Cu}$ having atomic number $29,3 \mathrm{~d}^{9} 4 \mathrm{~s}^{2}$ (ground state) having unfilled d orbital and fully filled s orbital. But instead of exhibiting this electronic configuration, it exhibits anomalous configuration having fully filled $\mathrm{d}$ orbital and partially filled s orbital, as the full $3 \mathrm{~d}$ orbital is more stable than a full $4 \mathrm{~s}$ orbital. This configuration causes the alignment of spin of the electrons resulting in long-range ferromagnetic order in $\mathrm{Cu}$ doped $\mathrm{ZnO}$. Doping at the $3 \mathrm{~d}$ transition metal site by transition metal ions in $\mathrm{ZnO}$ lattice has observed a variety of magnetic and electronic orders with spatially correlated charge spin and orbital degree of freedom. Hence, enhanced dielectric constant is observed.

6.1.2. Rare Earth Metal-Doped $\mathrm{ZnO}$. Rare earth metal-, Ce [139], Gd [130, 140], La [141], Nd [142], Ho [143], Er [144], and $\mathrm{Tm}$ [145], doped $\mathrm{ZnO}$ nanoparticles have been discussed for their dielectric studies in this article.

Figure 8 shows the variation of the dielectric constant of various rare earth metal-doped $\mathrm{ZnO}$ nanoparticles with respect to frequency in the range of $0 \mathrm{~Hz}$ to $10 \mathrm{MHz}$. In the graph, it has been observed that the value of the dielectric constant of every rare metal-doped $\mathrm{ZnO}$ is high at low frequencies since all four sources of polarization are active at 


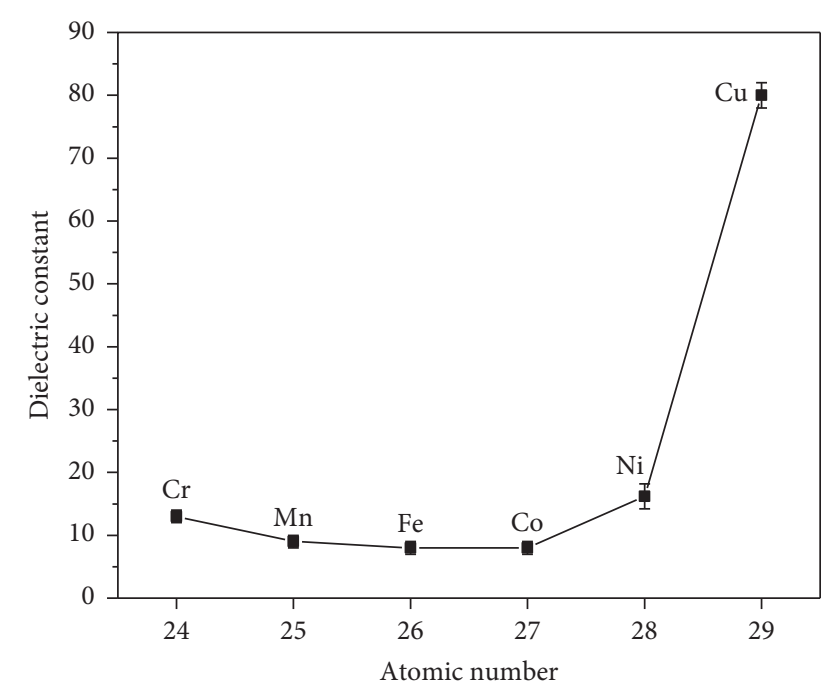

FIGURE 7: Variation of the dielectric constant of various transition metal-doped $\mathrm{ZnO}$ nanoparticles at 5\% doping and at $1 \mathrm{MHz}$ frequency with respect to their atomic number.

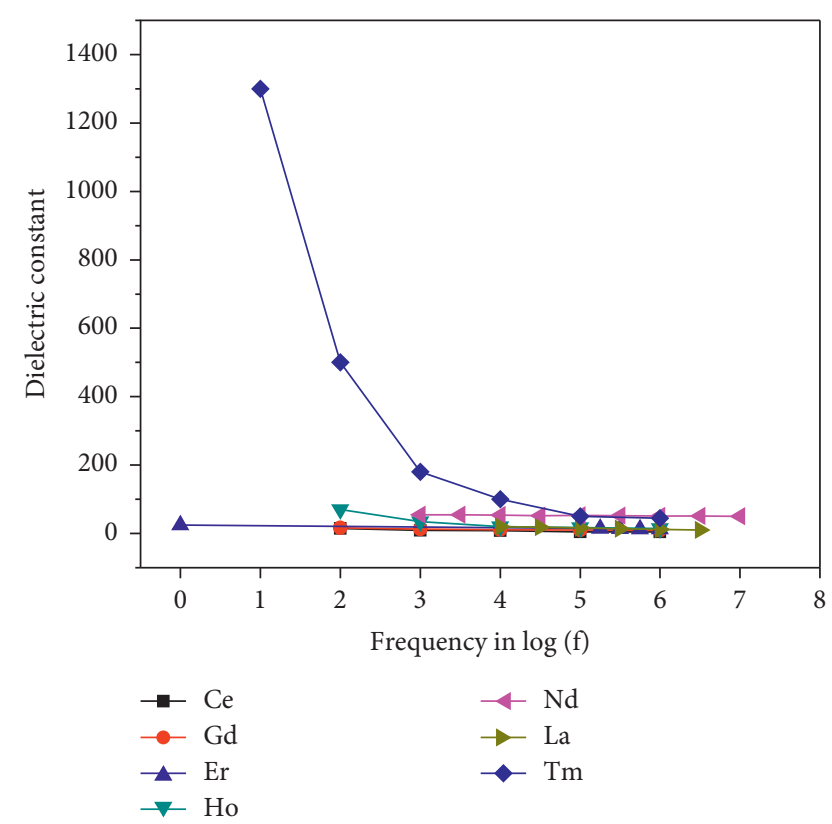

FIGURE 8: Variation of the dielectric constant of various rare earth metal-doped $\mathrm{ZnO}$ nanoparticles with respect to frequency.

low frequencies. $\mathrm{ZnO}$ is a polar molecule so all the dipoles get aligned in the direction of the applied electric field and give rise to a higher value of $k$. As the frequency increases, the value of $k$ starts decreasing and after a particular frequency it becomes constant, as hopping between different metal ions cannot follow the alternating field. Hence, the value of $k$ decreases at high frequencies [141-145]. The phenomena of dielectric dispersion are attributed to the Maxwell-Wagner model. Among all the rare earth metals discussed in this article, Tm is showing a significant dielectric dispersion. The value of $k$ is very high at low frequencies because $\mathrm{Tm}$ is highly polarizable and a higher value of $k$ at low frequencies can be explained based on interfacial polarization due to inhomogeneous structure and defects like oxygen vacancies and grain boundary defects.

(1) Effect of Rare Earth Metal Doping Concentration on Dielectric Constant. Figure 9 shows the variation of $k$ for some rare earth metal-doped $\mathrm{ZnO}$ nanoparticles with different doping concentrations at $1 \mathrm{MHz}$ frequency. In Cedoped $\mathrm{ZnO}$ nanoparticles, initially, the value of $k$ decreases due to the high density of defects. But a further increase in doping concentration increases the value of $k$ due to less electronegativity of $\mathrm{Ce}$ than $\mathrm{Zn}$ that makes the ionic bonds weaker [139]. The dielectric constant of Gd-doped $\mathrm{ZnO}$ nanoparticles decreases with the increase in doping concentration due to a decrease in relaxation time where ionic and orientational polarization are closely connected with each other. Gd acts as an acceptor and absorbs free charge carriers, hence decreasing the value of $k$ [130].

A larger ionic radius of $\mathrm{Nd}^{3+}$ ions substituted for $\mathrm{Zn}^{2+}$ ions in $\mathrm{Nd}$-doped $\mathrm{ZnO}$ indicates local distortion in the doped $\mathrm{ZnO}$ lattice, due to which, initially, the value of $k$ increases with doping but as the doping concentration is increased further, the sample becomes porous and hence the value of $k$ starts decreasing, as these pores get filled with air which has low dielectric constant, hence decreasing the overall dielectric constant of the doped sample [142].

The value of $k$ in Ho-doped $\mathrm{ZnO}$ increases monotonically with the increase in doping concentration. This is because the decrease in columbic interaction causes an increase in exciton binding energy which leads to an increase in the value of $k$ [143]. The value of $k$ in Er-doped $\mathrm{ZnO}$ nanoparticles varied according to its size. Initially, up to $3 \%$ of doping, the value of $k$ decreased and then it increased again because initially the nanoparticles had a rod-like structure and with the further increase in concentration, it started to change into a plate-like structure. Hence, the value of $k$ started to increase with the increase in the concentration of $\operatorname{Er}[144]$.

(2) Effect of Atomic Number of Rare Earth Metal on Dielectric Constant. Figure 10 shows the variation of $k$ value of various rare earth metal-, La [141], Ce [139], Nd [142], Gd [140], Er [144], and $\mathrm{Tm}$ [145], doped $\mathrm{ZnO}$ nanoparticles at 5\% doping and at $1 \mathrm{MHz}$ frequency with respect to their atomic number. It has been observed that the value of $k$ of various rare earth metal-doped $\mathrm{ZnO}$ nanoparticles increases exponentially as atomic number increases from 57 to 69. Significant enhancement in the dielectric constant of Tm-doped $\mathrm{ZnO}$ is due to the anomalous electronic configuration of $\mathrm{Tm}$ having atomic number $69,4 \mathrm{f}^{13} 6 \mathrm{~s}^{2}$ (ground state) having unfilled $f$ orbital and fully filled $s$ orbital. But instead of exhibiting this electronic configuration, it exhibits anomalous configuration having fully filled $\mathrm{f}$ orbital and partially filled s orbital as the full $4 \mathrm{f}$ orbital is more stable than a full $6 \mathrm{~s}$ orbital. This configuration causes the alignment of the spin of the electrons resulting in long-range ferromagnetic order in $\mathrm{Tm}$ doped $\mathrm{ZnO}$. Doping at the posttransition metal site by rare earth ions in $\mathrm{ZnO}$ lattice has observed a variety of magnetic and electronic orders with spatially correlated 


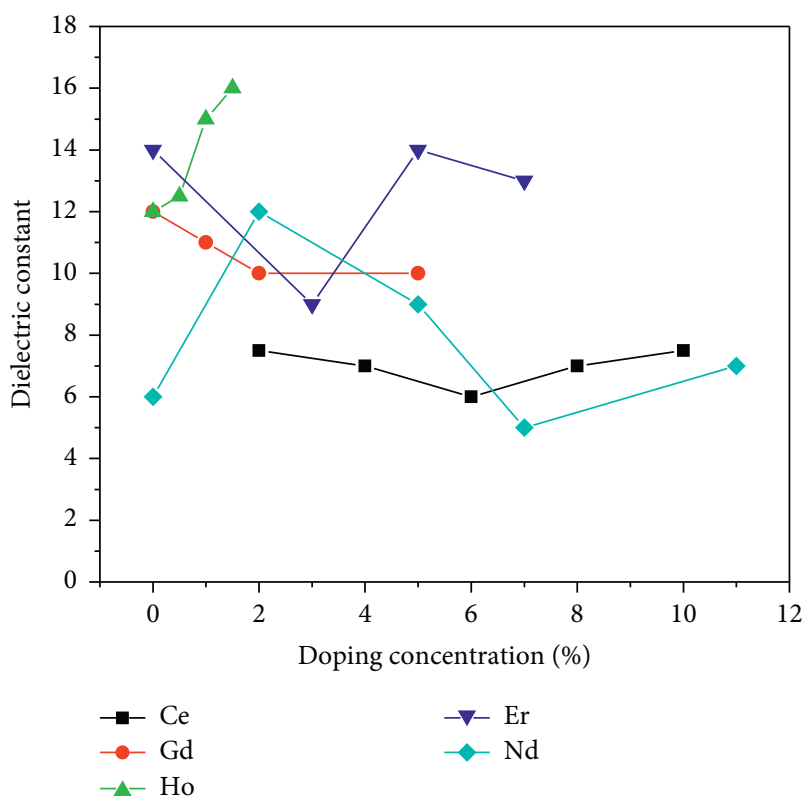

FIGURE 9: Variation of dielectric constant of rare earth metal-doped $\mathrm{ZnO}$ nanoparticles with respect to doping concentration at $1 \mathrm{MHz}$ frequency.

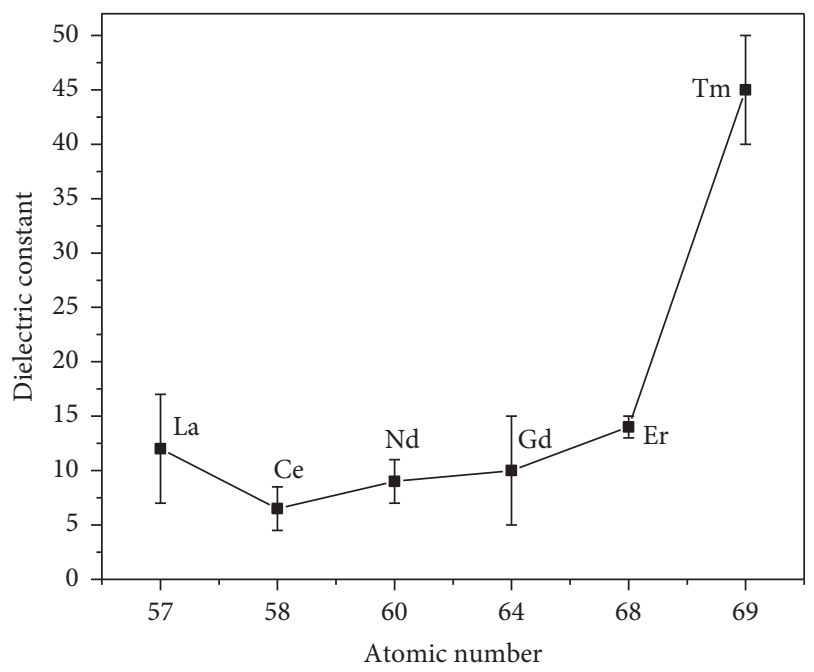

FIGURE 10: Variation of the dielectric constant of various rare earth metal-doped $\mathrm{ZnO}$ nanoparticles at 5\% doping and at $1 \mathrm{MHz}$ frequency with respect to their atomic number.

charge spin and orbital degrees of freedom. Hence, large ferromagnetism and enhanced dielectric constant are observed.

Table 3 expresses the value of $k$ of various metal-doped $\mathrm{ZnO}$ nanoparticles for 5\% doping at an operating frequency of $1 \mathrm{MHz}$ and their respective electronic applications. The graph in Figure 11 shows that $\mathrm{Cu}$ among transition metals and Tm among all the rare earth metals discussed in this article attain the highest value of $k, 80$ and 45 , respectively, at $5 \%$ doping and at $1 \mathrm{MHz}$ frequency.

\section{Polymer}

Polymers are of great attraction for researchers due to various interesting properties like low cost, flexibility, lightweight, easy processing, and wide range of operating frequency [35]. Petrochemical plastics were used widely in consumer-based products, food packaging, lightings, automobiles, and many electronic applications such as printed circuit board (PCB) due to their easy modification of shape, structure, and properties [146].

7.1. Polymer Nanocomposites. The small size particles called nanofillers are used to distribute into the polymer matrix which acts as a flexible base matrix which gives rise to a polymer nanocomposite $[147,148]$. So, the properties of a composite material are greatly affected by the choice of polymer matrix and the nanofiller. Polymer-based nanocomposites have many applications in the field of medical and engineered technology due to their good electron transport and mechanical and optical properties [149, 150]. They are good aspirants for energy storage applications. Degradation resistance improved thermal and mechanical properties along with improved dielectric breakdown strength being the added advantages of polymer nanocomposites [151, 152].

7.1.1. Polymer-Based $\mathrm{ZnO}$ Nanocomposites. A lot of work is done to explore the dielectric and electrical properties of polymer nanocomposites. Figure 12 shows the variation of the dielectric constant of various polymer-based $\mathrm{ZnO}$ nanocomposites with respect to frequency in the range of $0 \mathrm{~Hz}$ to $1 \mathrm{MHz}$. In the graph, it has been observed that the value of the dielectric constant of every polymer-based $\mathrm{ZnO}$ nanocomposite is high at low frequencies because all four sources of polarization are active at low frequencies and $\mathrm{ZnO}$ is a polar molecule, so all the dipoles get aligned in the direction of applied electric field and thus give rise to a higher value of $k$. As the frequency increases, the value of $k$ starts decreasing and after a particular frequency, it becomes constant since dipoles cannot follow the alternating field and are unable to align themselves in the direction of the electric field. Hence, the value of $k$ decreases at high frequencies [141-145]. The dielectric dispersion in the case of polymer nanocomposites is attributed to Maxwell-Wagner-Sillars (MWS) effect which represents the collection of charge at the interfaces of materials having different conductivity which leads to increased polarizability in the composite material [153].

In ethylene-vinyl acetate (EVA)/ZnO nanocomposite, the larger value of dielectric constant at low frequencies is due to the space change polarization which arises because of impurities and defects present in the nanocomposite [38]. In case of polyvinyl chloride (PVC)/ZnO nanocomposite, the value of dielectric constant is high at low frequencies and the value starts decreasing as the frequency is increased. This is 
TABLE 3: Various metal-doped $\mathrm{ZnO}$ nanoparticles and their potential applications.

\begin{tabular}{lcccc}
\hline Metal & $\begin{array}{c}\text { Doping } \\
(\%)\end{array}$ & $\begin{array}{c}\text { Frequency } \\
(\mathrm{MHz})\end{array}$ & $\begin{array}{c}\text { Dielectric constant of metal-doped ZnO } \\
\text { nanoparticles }\end{array}$ & Applications \\
\hline $\mathrm{Ce}$ & 5 & 1 & 6.5 & $\begin{array}{c}\text { High-frequency device applications } \\
\text { Nano-optoelectronic applications } \\
\text { Optical applications } \\
\mathrm{Fe}\end{array}$ \\
$\mathrm{Co}$ & 5 & 1 & 8 & Spintronic applications \\
$\mathrm{Mn}$ & 5 & 1 & 8 & Pressure sensors, piezoelectric nanogenerators for \\
$\mathrm{Nd}$ & 5 & 1 & 9 & energy harvesting \\
$\mathrm{La}$ & 5 & 1 & 9 & Storage applications \\
$\mathrm{Cr}$ & 5 & 1 & 12 & LEDs, optoelectronic devices \\
$\mathrm{Er}$ & 5 & 1 & 13 & High-frequency device applications \\
$\mathrm{Ni}$ & 5 & 1 & 14 & Optoelectronic applications \\
$\mathrm{Tm}$ & 5 & 1 & 16.2 & Dye-sensitized solar cell applications. \\
$\mathrm{Cu}$ & 5 & 1 & 45 & High dielectric constant applications \\
\hline
\end{tabular}

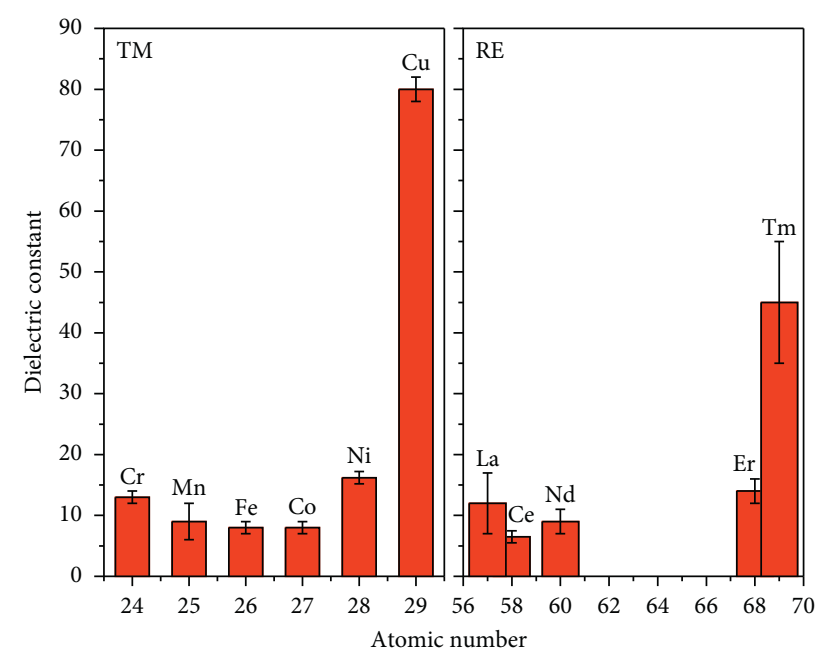

Figure 11: Dielectric constant of various metal-doped $\mathrm{ZnO}$ nanoparticles for $5 \%$ doping at $1 \mathrm{MHz}$ frequency.

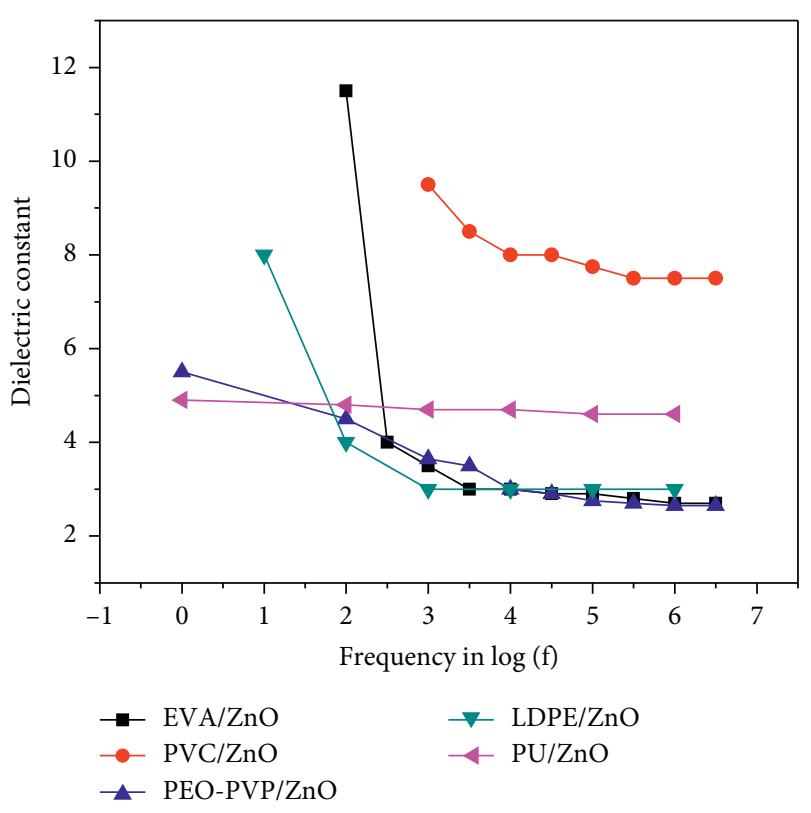

FIGURE 12: Variation of the dielectric constant of various polymerbased $\mathrm{ZnO}$ nanocomposites with respect to frequency. due to the reduction in orientational polarization at high frequencies [154]. In poly(ethylene oxide) (PEO) poly(vinylpyrrolidone) (PVP) blend matrix $\mathrm{PEO}-\mathrm{PVP} / \mathrm{ZnO}$ nanocomposite, the larger value of $k$ at low frequencies is attributed to the interfacial polarization in the nanocomposite material [155]. In case of low-density polyethylene (LDPE)/ $\mathrm{ZnO}$ nanocomposite, the value of dielectric constant is higher at low frequencies due to the presence of interfacial polarization and as the frequency increases, the value of $k$ decreases as interfacial polarization is no longer active at high frequencies [156].

Figure 13 shows the variation of $k$ of the above-discussed polymer $\mathrm{ZnO}$ nanocomposites with different doping concentrations at $1 \mathrm{KHz}$ frequency. In every polymer nanocomposite, the value of $k$ increases as the concentration of $\mathrm{ZnO}$ nanofiller is increased, this is because these polymers have a low dielectric constant as compared to the $\mathrm{ZnO}$ nanoparticles. So, when a composite is prepared with $\mathrm{ZnO}$ as a nanofiller, the effective value of $k$ of the polymer nanocomposite is increased. And as the concentration is increased, the effective value of $k$ further increases. Along with this, homogeneous dispersion of nanofillers in the polymer matrix are required to ensure that there is no agglomeration 


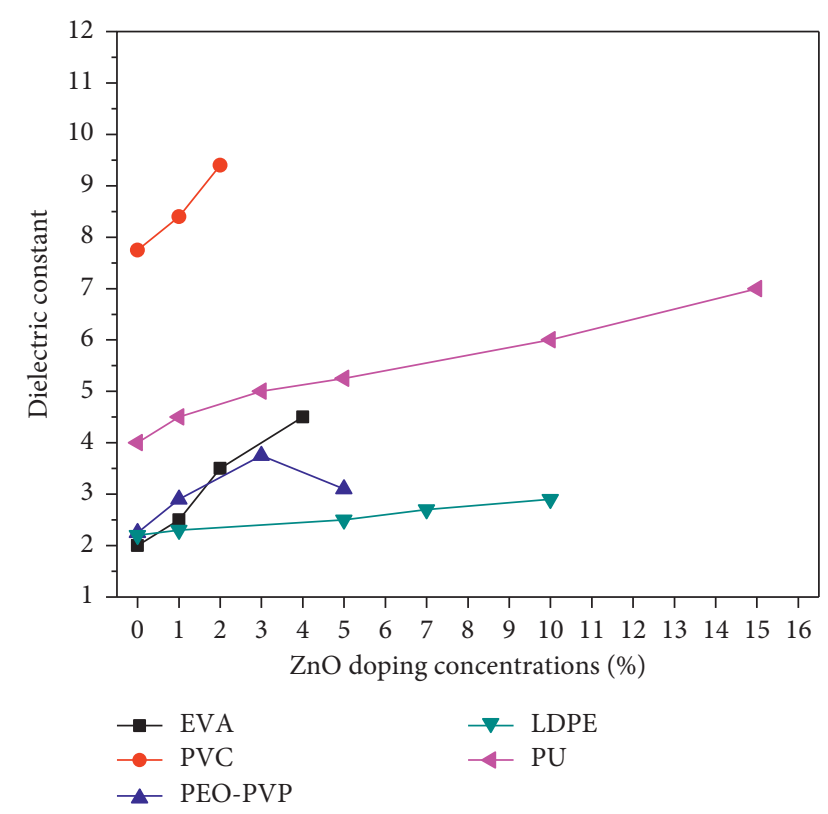

FIGURE 13: Variation of the dielectric constant of various polymerbased $\mathrm{ZnO}$ nanocomposites with respect to doping concentration at $1 \mathrm{KHz}$ frequency.

of nanoparticles that provide tunnelling, hence reducing the dielectric breakdown strength of polymer nanocomposite [157]. In case of PEO-PVP/ZnO nanocomposite, the value of $k$ increases up to $3 \%$ filler concentration due to the fact that the dielectric constant of PEO-PVP is less than $\mathrm{ZnO}$ nanoparticles hence with the addition of $\mathrm{ZnO}$, there is an increase in the effective dielectric constant of the polymer nanocomposite. But after that at $5 \%$, it started decreasing which may be due to the electrostatic interaction between functional groups of polymer blend and $\mathrm{ZnO}$ nanoparticles resulting in a reduction of the orientation of dipoles, hence resulting in reduced dielectric polarization in the nanocomposite. In case of $\mathrm{PU} / \mathrm{ZnO}$ and $\mathrm{LDPE} / \mathrm{ZnO}$ nanocomposite, the value of $k$ increases very linearly with the increase in the concentration of $\mathrm{ZnO}$ nanoparticles. But in case of EVA/ZnO and PVC/ZnO nanocomposite, an abrupt change in $k$ is observed with the increase in the concentration of $\mathrm{ZnO}$ nanoparticles. Due to the lack of availability of data points in the literature, a conclusion cannot be made if the values of the dielectric constant will increase exponentially or like a parabola with the increase in concentration. Hence, in case of polymer-based $\mathrm{ZnO}$ nanocomposites, there is still room available to study the effect of concentration on the dielectric properties.

7.1.2. Applications of Polymer Nanocomposites. Polymer nanocomposites are used in several electronic applications due to their promising electrical, dielectric, optical, and mechanical properties. Polymer nanocomposites are used in the devices like organic field effect transistors [158-161], gas sensors [162-166], solar cells [167-171], high power and high storage density capacitors and supercapacitors [172-177], electromagnetic interference shielding [178], thermochromic and electrochromic devices [179], electronic antenna [180], optoelectronic devices [181], high capacity memory devices [182], insulating materials [183, 184], nanodielectric applications $[185,186]$, and printed circuit board [187-189].

7.2. Biodegradable Polymers. Although polymer nanocomposites show very good and promising dielectric properties and enhanced dielectric breakdown strength, the biggest disadvantage is the toxic nature of petroleum-based polymers. When the devices or products made up of petroleum-based polymers are disposed of, they contaminate the environment, which is harmful to living organisms and human beings [97]. So, the electronic products are required to be made up of a material which is biocompatible and biodegradable and is safe for human beings along with other living organisms, hence promoting the green technology.

7.2.1. Biodegradable Polymer Nanocomposites. Nowadays, biofriendly or echo-friendly materials are high in demand in every field as they are nontoxic $[38,190]$. Biodegradable polymer nanocomposite is a category of materials that have very interesting properties compared to pure biodegradable polymers and old composites. They have all the properties and advantages of polymers, but an additional advantage is that they are biodegradable. Biodegradable polymers are made up of living organism's protein and DNA. Biodegradable polymers nanocomposites are doing very well in various fields. They are used for food packaging to improve the shelf life of food [191-193], as a photocatalyst to purify water [194, 195], cancer treatments [196-198], drug delivery in the medical field [199-201], antimicrobial activities [202-204], tissue engineering [205], and sensors [206, 207].

Various researchers have made use of biodegradable polymers to develop some new biodegradable nanocomposites. There are various biodegradable polymers like poly(3-hydroxybutyrate) (PHB), polylactic acid (PLA), polycaprolactone (PCL), poly(butylene succinate) (PBS), poly(butylene adipate-co-terephthalate) (PBAT), poly(3hydroxybutyrate-co-3-hydroxyvalerate) (PHBV), (poly-lactide-co-glycolide) (PLGA), chitosan, cellulose, and gluten.

These are $100 \%$ biodegradable polymers, and they have several applications in different areas. Polyhydroxyalkanoates (PHA) is a class of polymers which is made from renewable sources synthesized by bacteria from carbon and oxygen [208, 209]. In this class, PHB is the most widely studied and useful biopolymer. But it has some disadvantages like it is very brittle, cost of production is very high, it does not have any resistance to thermal degradation, and it has a high melting point, due to which it is not suitable for industrial applications [209-212].

7.2.2. Biodegradable Polymer-Based ZnO Nanocomposites and Their Applications. All the LEDs emit UV radiations in addition to visible light which is very harmful to the living organisms [213]. Poly(3-hydroxybutyrate-co-3-hydroxyvalerate) (PHBV) polymer/ZnO nanocomposite provides 
the absorption of entire UV region. This enables the material to be used as an encapsulation material for LEDs [190]. This material absorbs all the UV radiation spectra and emits only visible light. The PHB-ZnO nanocomposite material can be used in textile industry for UV blocking applications [214-216]. The same material can also be used to manufacture printed circuit boards (PCB) which are nontoxic and do not contaminate the environment when disposed off [190]. The material is good for antibacterial applications [217]. PHBV and $\mathrm{ZnO}$ nanocomposite is very good for food packaging applications [218-221]. Enhanced value of dielectric constant of polylactide acid (PLA) and poly(butylene adipate-co-terephthalate) (PBAT) with graphene nanocomposites is useful for EMI shielding applications [222, 223]. Poly(butylene succinate) (PBS) and $\mathrm{ZnO}$ nanocomposite films are very suitable material for food packaging to improve the shelf life of packed food due to its good antimicrobial and mechanical properties [224].

Enhancement in mechanical, antimicrobial, and dielectric properties of chitosan $/ \mathrm{ZnO}$ nanocomposite films with the increase of $\mathrm{ZnO}$ concentration is very good for food packaging applications [225-227]. Chitosan-ZnO/polyaniline ternary nanocomposite material is recommended for storage of charge in supercapacitors [228]. Chitosan is a nontoxic, biocompatible, and biodegradable polymer which is obtained from shells of lobsters or crabs and also in the cell walls of fungi. It has antimicrobial and UV protection properties as well [229-231]. The enhanced photoluminescence intensity of the Chitosan capped $\mathrm{ZnO}$ nanocomposite makes the material suitable for display devices and biomedical applications [125, 232, 233].

7.3. Future Aspects. The field of biodegradable nanocomposites is still being explored because it has a lot more to give to the society and electronic industry:

(1) Higher value of dielectric constant for $\mathrm{ZnO}$ nanoparticles can be achieved by doping it with some rare earth metals or transition metals. As $\mathrm{ZnO}$ is a nontoxic material, it is safe for the human being and the environment to be used in electronic products like thin-film transistors, memory cells, and highspeed integrated circuits.

(2) Keeping in mind environmental safety there is a need to design and synthesize nontoxic and biodegradable dielectric material for energy storage applications. Hence, ZnO-based biodegradable polymer nanocomposites can be used as a dielectric material for developing energy storage devices like capacitors to enhance their energy density.

(3) To enhance the energy storage density, a multilayered structure of $\mathrm{ZnO}$-based biodegradable polymer nanocomposite can be developed to achieve a higher value of energy density.

(4) A sandwiched structure of $\mathrm{ZnO}$-based biodegradable polymer nanocomposites with different concentrations of $\mathrm{ZnO}$ nanoparticles as filler in the biodegradable polymer as the base matrix can be used to enhance the energy density of the material further.

\section{Conclusion}

Dielectric constant is a very important factor of a material which determines its applications in the electronic industry as a capacitor, thin-film transistor, memory devices, highspeed IC packaging, and EMI shielding. $\mathrm{ZnO}$ is one of the most demanded materials in the electronic industry due to its very attractive properties like wide availability, nontoxicity, and cost-effectiveness. Nanocomposites of $\mathrm{ZnO}$ have been explored by various researchers. Two groups of metals, transition metal and rare earth metal, have been chosen to be a dopant in $\mathrm{ZnO}$ for this review. The literature revealed that the value of the dielectric constant of a synthesized material depends upon various factors. The first factor is the size of nanoparticles of synthesized material, the larger the size of nanoparticles, the higher will be the value of dielectric constant due to the fact that larger particle contains a greater number of dipoles which get aligned under the influence of the electric field. Second, the thickness of films also affects the value of the dielectric constant. The value increases with the increase in the film thickness of $\mathrm{ZnO}$ thin films due to the quantum confinement effect. Third, the density of the material: if the material is porous, the value of the dielectric constant will be less and if the material is of high density, the value of the dielectric constant will be high. Fourth, operating frequency: at low frequency the value of the dielectric constant is high and at high frequencies, the value becomes low for every material since all four sources of polarization are active at low frequencies, and at high frequencies, the dipoles are unable to align themselves with the changing direction of the applied field. Fifth, the defects in the material, such as oxygen vacancies, zinc interstitials, and inhomogeneities like grain boundaries, are inherent to the synthesis process of the material. The higher the defects, the higher will be the value of dielectric constant of the material at low frequencies.

Among all the metals discussed in this article, transition metal $\mathrm{Mn}$ and rare earth metal $\mathrm{Tm}$ are showing a significant dielectric dispersion. The higher value of $k$ at low frequencies can be explained based on interfacial polarization due to inhomogeneous structure and defects such as oxygen vacancies and grain boundary defects. The exponential increase in the dielectric constant of $\mathrm{Cu}$ among transition metals and $\mathrm{Tm}$ among rare earth metal-doped $\mathrm{ZnO}$ at the same doping concentration is due to the anomalous electronic configuration.

Petroleum-based polymer $\mathrm{ZnO}$ nanocomposites are also observed to show promising dielectric properties. But they lag due to their toxic nature which contaminates the environment when they are disposed of. Biodegradable $\mathrm{ZnO}$ nanocomposites are explored by various researchers which shows good mechanical, antibacterial, antimicrobial, and dielectric properties which enabled these materials to be used as food packaging materials and in various medical 
applications. Still, there is much room available to study the effect of filler concentration on the dielectric properties of polymer $\mathrm{ZnO}$ nanocomposites. To experience all the advantages of a polymer material along with the nontoxicity, the dielectric properties of biodegradable $\mathrm{ZnO}$ nanocomposites need to be explored in depth so that these materials can be used in electronic applications as storage materials and many more electronic applications. Hence, electronic products need to be made up of the material, which is biocompatible, biodegradable, and safe for living organisms as well as human beings, hence promoting green technology.

\section{Data Availability}

The data used to support the findings of this study in the manuscript are available from the corresponding author upon request.

\section{Conflicts of Interest}

The authors declare that they have no conflicts of interest.

\section{Acknowledgments}

The authors are thankful to the Electronics and Communication Engineering Department of UIET, Punjab University, for providing the facilities to carry out this research work.

\section{References}

[1] W. R. Tinga and S. O. Nelson, "Dielectric properties of materials for microwave processing-tabulated," Journal of Microwave Power, vol. 8, no. 1, pp. 23-65, 1973.

[2] X. Huang and P. Jiang, "Core-shell structured high- $k$ polymer nanocomposites for energy storage and dielectric applications," Advanced Materials, vol. 27, no. 3, pp. 546-554, 2015.

[3] J. Robertson and R. M. Wallace, "High- K materials and metal gates for CMOS applications," Materials Science and Engineering: R: Reports, vol. 88, pp. 1-41, 2015.

[4] R. Singh and R. K. Ulrich, "High and low dielectric constant materials," The Electrochemical Society Interface, vol. 8, p. 26, 1999.

[5] H. S. Nalwa, Hand Book of Low and High Dielectric Constant Materials and Their Applications, Academic Press, Ibaraki, Japan, 1999.

[6] S. Park, C.-H. Kim, W.-J. Lee, S. Sung, and M.-H. Yoon, “Solgel metal oxide dielectrics for all-solution-processed electronics," Materials Science and Engineering: R: Reports, vol. 114, pp. 1-22, 2017.

[7] X. Huang, Z. Pu, L. Tong, Z. Wang, and X. Liu, "Preparation and dielectric properties of surface modified $\mathrm{TiO}_{2} / \mathrm{PEN}$ composite films with high thermal stability and flexibility," Journal of Materials Science: Materials in Electronics, vol. 23, no. 12, pp. 2089-2097, 2012.

[8] R. P. Ortiz, A. Facchetti, and T. J. Marks, "High- $k$ organic, inorganic, and hybrid dielectrics for low-voltage organic field-effect transistors," Chemical Reviews, vol. 110, no. 1, pp. 205-239, 2010.
[9] V. S. Jahnavi, S. K. Tripathy, and A. V. N. Ramalingeswara Rao, "Structural, optical, magnetic and dielectric studies of $\mathrm{SnO}_{2}$ nano particles in real time applications," Physica B: Condensed Matter, vol. 565, pp. 61-72, 2019.

[10] S. Sarmah and A. Kumar, "Optical properties of $\mathrm{SnO}_{2}$ nanoparticles," Indian Journal of Physics, vol. 84, no. 9, pp. 1211-1221, 2010.

[11] E. Pradyumna, N. Sreelekha, D. Amaranatha Reddy, K. R. Gunasekhar, and K. Subramanyam, "Dopant induced room temperature ferromagnetism in spintronic $\mathrm{SnO}_{2}$ : Co nanoparticles," The International Journal of Advanced Engineering and Nano Technology, vol. 2, p. 22, 2015.

[12] Q. Zhao, L. Ma, Q. Zhang, C. Wang, and X. Xu, " $\mathrm{SnO}_{2}$-Based nanomaterials: synthesis and application in lithium-ion batteries and supercapacitors," Journal of Nanomaterials, vol. 2015, Article ID 850147, 15 pages, 2015.

[13] X. W. Lou, Y. Wang, C. Yuan, J. Y. Lee, and L. A. Archer, "Template-free synthesis of $\mathrm{SnO}_{2}$ hollow nanostructures with high lithium storage capacity," Advanced Materials, vol. 18, no. 17, pp. 2325-2329, 2006.

[14] H. J. Van Daal, "The static dielectric constant of $\mathrm{SnO}_{2}$," Journal of Applied Physics, vol. 39, no. 9, pp. 4467-4469, 1968.

[15] A. Ahmed, P. Tripathi, M. Naseem Siddique, and T. Ali, "Microstructural, optical and dielectric properties of Alincorporated $\mathrm{SnO} 2$ nanoparticles," IOP Conference Series: Materials Science and Engineering, vol. 225, Article ID 012173, 2017.

[16] C. Madhu, I. Kaur, and N. Kaur, "Synthesis and investigation of photonic properties of surface modified $\mathrm{ZnO}$ nanoparticles with imine linked receptor as coupling agent- for application in LEDs," Journal of Materials Science: Materials in Electronics, vol. 28, no. 9, pp. 6388-6398, 2017.

[17] T. Xiao, B. Heng, X. Hu, and Y. Tang, "In situ CVD synthesis of wrinkled scale-like carbon arrays on $\mathrm{ZnO}$ template and their use to supercapacitors," The Journal of Physical Chemistry C, vol. 115, no. 50, pp. 25155-25159, 2011.

[18] S. Shi, X. Zhuang, B. Cheng, and X. Wang, "Solution blowing of $\mathrm{ZnO}$ nanoflake-encapsulated carbon nanofibers as electrodes for supercapacitors," Journal of Materials Chemistry A, vol. 1, no. 44, pp. 13779-13788, 2013.

[19] D. Bresser, F. Mueller, M. Fiedler et al., "Transition-metal-doped zinc oxide nanoparticles as a new lithium-ion anode material," Chemistry of Materials, vol. 25, no. 24, pp. 4977-4985, 2013.

[20] J. Wang, R. Chen, L. Xiang, and S. Komarneni, "Synthesis, properties and applications of $\mathrm{ZnO}$ nanomaterials with oxygen vacancies: a review," Ceramics International, vol. 44, no. 7, pp. 7357-7377, 2018.

[21] z. Guang, Handbook of Advanced Dielectric, Piezoelectric and Ferroelectric Materials Synthesis Properties and Applications, Woodhead Publishing, Sawston, UK, 2008.

[22] H. Treichel, A. Mitwalsky, G. Tempel et al., "Deposition, annealing and characterisation of high-dielectric-constant metal oxide films," Advanced Materials for Optics and Electronics, vol. 5, no. 3, pp. 163-175, 1995.

[23] P. Lunkenheimer, S. Krohns, S. Riegg, S. G. Ebbinghaus, A. Reller, and A. Loidl, "Colossal dielectric constants in transition-metal oxides," The European Physical Journal Special Topics, vol. 180, no. 1, pp. 61-89, 2009.

[24] K. Meher and K. B. R. Varma, "Colossal dielectric behavior of semiconducting Sr2TiMnO 6 ceramics," J. Appl. Phys.vol. 105, 2009.

[25] K. C. Kao, "Dielectric phenomena in solids: with emphasis on physical concepts of electronic processes," Electric 
Polarization and Relaxation, Dielectric Phenomena in Solids, vol. 10, pp. 41-114, 2004.

[26] P. Balk, "Dielectrics in microelectronics - problems and perspectives," Journal of Non-crystalline Solids, vol. 187, pp. 1-9, 1995.

[27] H. Treichel, E. Eckstein, and W. Kern, "New dielectric materials and insulators for microelectronic applications," Ceramics International, vol. 22, no. 5, pp. 435-442, 1996.

[28] S. Vyas, "A short review on: optimization techniques of $\mathrm{ZnO}$ based thin film transistors," Chinese Journal of Physics, vol. 56, no. 1, pp. 117-124, 2018.

[29] P. Capacitor: Chapter 5 Capacitance and Dielectrics.

[30] J. G. Kirkwood, "On the theory of dielectric polarization," The Journal of Chemical Physics, vol. 4, no. 9, pp. 592-601, 1936.

[31] R. Dorey, "Microstructure-property relationships," Ceramic Thick Films for MEMS and Microdevices, vol. 39, pp. 85-112, 2012.

[32] V. Sundar, R. E. Newnham, and R. E. Newnham, "Electrostriction and polarization," Ferroelectrics, vol. 135, no. 1, pp. 431-446, 1992.

[33] A. S. Lanje, S. J. Sharma, R. S. Ningthoujam, J.-S. Ahn, and R. B. Pode, "Low temperature dielectric studies of zinc oxide $(\mathrm{ZnO})$ nanoparticles prepared by precipitation method," Advanced Powder Technology, vol. 24, no. 1, pp. 331-335, 2013.

[34] P. Boussard, P. E. M. Siegbahn, and U. Wahlgren, "Cluster models of zinc oxide including ionic and covalent effects," Adsorption on Ordered Surfaces of Ionic Solids and Thin Films, vol. 33, pp. 192-205, 1993.

[35] M. L. Singla, R. Sehrawat, N. Rana, and K. Singh, "Dielectric behaviour of emeraldine base polymer- $\mathrm{ZnO}$ nanocomposite film in the low to medium frequency," Journal of Nanoparticle Research, vol. 13, no. 5, pp. 2109-2116, 2011.

[36] K. Omar, M. D. Johan Ooi, and M. M. Hassin, "Investigation on dielectric constant of zinc oxide," Modern Applied Science, vol. 3, pp. 110-116, 2009.

[37] I. Latif, E. AL-Abodi, J. Al Khafagi, and K. Al, "Preparation, characterization and electrical study of (carboxymethylated polyvinyl alcohol/ZnO) nanocomposites," American Journal of Polymer Science, vol. 2, no. 6, pp. 135-140, 2013.

[38] J. Sebastian, E. T. Thachil, J. J. Mathen et al., "Enhancement in the electrical and thermal properties of ethylene vinyl acetate (EVA) co-polymer by zinc oxide nanoparticles," Open Journal of Composite Materials, vol. 05, no. 03, pp. 79-91, 2015.

[39] A. F. Mansour, S. F. Mansour, and M. A. Abdo, "Enhancement of structural and electrical properties of $\mathrm{ZnO}$ / PVA nanocomposites," IOSR Journal of Applied Physics, vol. 7, pp. 97-106, 2015.

[40] H. Singh, A. Bharti, N. Goyal, and P. S. Gill, "Metallic/ chalcogen dual phase effects on dielectric relaxations, resonance and spectroscopic impedance in amorphous chalcopyrite CuxInyGa10Se70-xTe20-y thin films," Journal of Materials Science: Materials in Electronics, vol. 29, no. 17, pp. 14406-14415, 2018.

[41] A. K. Jonscher, "Dielectric relaxation in solids," Journal of Physics: Applied Physics, vol. 32, 1999.

[42] K. S. Cole and R. H. Cole, "Dispersion and absorption in dielectrics I. alternating current characteristics," The Journal of Chemical Physics, vol. 9, no. 4, pp. 341-351, 1941.

[43] J. Charles Pravin, D. Nirmal, P. Prajoon, N. Mohan Kumar, and J. Ajayan, "Investigation of 6T SRAM memory circuit using high-k dielectrics based nano scale junctionless transistor," Superlattices and Microstructures, vol. 104, pp. 470-476, 2017.

[44] W. Raza, F. Ali, N. Raza et al., "Recent advancements in supercapacitor technology," Nano Energy, vol. 52, pp. 441473, 2018.

[45] D.-B. Ruan, P.-T. Liu, Y.-C. Chiu et al., "Investigation of low operation voltage in $\mathrm{ZnSnO}$ thin-film transistors with different high- $k$ gate dielectric by physical vapor deposition," Thin Solid Films, vol. 660, pp. 885-890, 2018.

[46] A. Abolghasemi Mahani, S. Motahari, and V. Nayyeri, "Synthesis, characterization and dielectric properties of onestep pyrolyzed/activated resorcinol-formaldehyde based carbon aerogels for electromagnetic interference shielding applications," Materials Chemistry and Physics, vol. 213, pp. 492-501, 2018.

[47] S. Devaraju, M. R. Vengatesan, M. Selvi, J. K. Song, and M. Alagar, "Mesoporous silica reinforced cyanate ester nanocomposites for low $\mathrm{k}$ dielectric applications," Microporous and Mesoporous Materials, vol. 179, pp. 157-164, 2013.

[48] M. Kobayashi, "More than moore," The Journal of The Institute of Image Information and Television Engineers, vol. 70, no. 3, pp. 324-327, 2016.

[49] F. Wu: P-25 Improved electrical performance of organic thin-film transistors with modified high- $\mathrm{K}$ dielectrics.

[50] A. Subramaniyam, C. Robinson, and A. John, "Fabrication of thin film transistor using high $K$ dielectric materials," International Journal of Engineering and Computer Science, vol. 3, no. 4, 2017.

[51] D. J. Dimaria, D. Arnold, and E. Cartier, "Degradation and breakdown of silicon dioxide films on silicon," Applied Physics Letters, vol. 61, no. 19, pp. 2329-2331, 1992.

[52] Y. Y. Yu, A. H. Jiang, and W. Y. Lee, "Organic/inorganic nano-hybrids with high dielectric constant for organic thin film transistor applications," Nanoscale Research Letters, vol. 11, p. 488, 2016.

[53] H. Zulkefle, L. N. Ismail, R. A. Bakar, M. H. Mamat, and M. Rusop, "Enhancement in dielectric constant and structural properties of sol-gel derived $\mathrm{MgO}$ thin film using $\mathrm{ZnO} /$ $\mathrm{MgO}$ multilayered structure," International Journal of Applied Physics and Mathematics, vol. 2, pp. 38-043, 2012.

[54] J. Li and X. Bi, "Temperature- and frequency-dependent dielectric behaviour of insulator/semiconductor (Al2O3/ $\mathrm{ZnO}$ ) nanolaminates with various $\mathrm{ZnO}$ thicknesses," Journal of Physics D: Applied Physics, vol. 49, 2016.

[55] H. Shinriki, T. Kisu, and S. Kimura, "Promising storage capacitor structures with thin $\mathrm{Ta} / \mathrm{sub} 2 / \mathrm{O} / \mathrm{sub} 5 /$ film for lowpower high-density DRAMs," IEEE Transactions on Electron Devices, vol. 37, 1990.

[56] Y. Gong, W. Zhou, Y. Kou, L. Xu, H. Wu, and W. Zhao, "Heat conductive h-BN/CTPB/epoxy with enhanced dielectric properties for potential high-voltage applications," High Voltage, vol. 2, no. 3, pp. 172-178, 2017.

[57] V. D. Mote, Y. Purushotham, and B. N. Dole, "Structural, morphological, physical and dielectric properties of $\mathrm{Mn}$ doped $\mathrm{ZnO}$ nanocrystals synthesized by sol-gel method," Materials \& Design, vol. 96, pp. 99-105, 2016.

[58] M. Parvez Ahmad, A. Venkateswara Rao, K. Suresh Babu, and G. Narsinga Rao, "Particle size effect on the dielectric properties of $\mathrm{ZnO}$ nanoparticles," Materials Chemistry and Physics, vol. 224, pp. 79-84, 2019.

[59] R. V. Mangalaraja, P. Manohar, F. D. Gnanam, and M. Awano, "Electrical and magnetic properties of $\mathrm{Ni} 0.8 \mathrm{Zn} 0.2 \mathrm{Fe} 2 \mathrm{O} 4 /$ silica composite prepared by sol-gel 
method," Journal of Materials Science, vol. 39, no. 6, pp. 2037-2042, 2004.

[60] R. L. De Sousa e Silva and A. Franco, "Effect of porosity on dielectric properties of $\mathrm{ZnO}$ ceramics," Journal of the European Ceramic Society, vol. 40, no. 4, pp. 1307-1311, 2020.

[61] D. J. Bergman, "The dielectric constant of a composite material-a problem in classical physics," Physics Reports, vol. 43, no. 9, pp. 377-407, 1978.

[62] B. Sareni, L. Krähenbühl, A. Beroual, and C. Brosseau, "Effective dielectric constant of random composite materials," Journal of Applied Physics, vol. 81, no. 5, pp. 2375-2383, 1997.

[63] G. A. Mohamed, A. B. Abd El-Moiz, and M. Rashad, "Lidoping effects on the electrical properties of $\mathrm{ZnO}$ films prepared by the chemical-bath deposition method," Physica B: Condensed Matter, vol. 370, no. 1-4, pp. 158-167, 2005.

[64] D. Huang, Z. Liu, Y. Li, and Y. Liu, "Colossal permittivity and dielectric relaxation of ( $\mathrm{Li}, \mathrm{In})$ co-doped $\mathrm{ZnO}$ ceramics," Journal of Alloys and Compounds, vol. 698, pp. 200-206, 2017.

[65] R. Khan, F. Zulfiqar, C. I. Levartoski de Araujo et al., "Influence of oxygen vacancies on the structural, dielectric, and magnetic properties of $(\mathrm{Mn}, \mathrm{Co})$ co-doped $\mathrm{ZnO}$ nanostructures," Journal of Materials Science: Materials in Electronics, vol. 29, no. 12, pp. 9785-9795, 2018.

[66] R. Silva, P. Banerjee, and A. Franco Júnior, "Functional properties of donor- and acceptor-co-doped high dielectric constant zinc oxide ceramics," Physical Chemistry Chemical Physics, vol. 21, no. 18, pp. 9456-9464, 2019.

[67] H. Kurnia and E. Suharyadi, "Study on the influence of crystal structure and grain size on dielectric properties of manganese ferrite $\left(\mathrm{MnFe}_{2} \mathrm{O}_{4}\right)$ nanoparticles," IOP Conference Series: Materials Science and Engineering, vol. 202, 2017.

[68] K. M. Lee, C. W. Lai, K. S. Ngai, and J. C. Juan, "Recent developments of zinc oxide based photocatalyst in water treatment technology: a review," Water Research, vol. 88, pp. 428-448, 2016.

[69] T. Cun, C. Dong, and Q. Huang, "Ionothermal precipitation of highly dispersive $\mathrm{ZnO}$ nanoparticles with improved photocatalytic performance," Applied Surface Science, vol. 384, pp. 73-82, 2016.

[70] K. N. Abbas and N. Bidin, "Morphological driven photocatalytic activity of $\mathrm{ZnO}$ nanostructures," Applied Surface Science, vol. 394, pp. 498-508, 2017.

[71] A. Akyol, H. C. Yatmaz, and M. Bayramoglu, "Photocatalytic decolorization of remazol red $\mathrm{RR}$ in aqueous $\mathrm{ZnO}$ suspensions," Applied Catalysis B: Environmental, vol. 54, pp. 19-24, 2004.

[72] G. Colon, M. C. Hidalgo, J. A. Navío, E. Pulido Melian, O. Gonzalez Díaz, and J. M. Dona Rodríguez, "Highly photoactive $\mathrm{ZnO}$ by amine capping-assisted hydrothermal treatment," Applied Catalysis B: Environmental, vol. 83, pp. $30-38,2008$.

[73] C. Lizama, J. Freer, J. Baeza, and H. D. Mansilla, “Optimized photodegradation of reactive blue 19 on $\mathrm{TiO}_{2}$ and $\mathrm{ZnO}$ suspensions," Catalysis Today, vol. 76, pp. 235-246, 2002.

[74] D. Mijin, M. Savic, P. Snezana et al., "A study of the photocatalytic degradation of metamitron in $\mathrm{ZnO}$ water suspensions," Desalination, vol. 249, pp. 286-292, 2009.

[75] A. K. Chandiran, M. Abdi-Jalebi, M. K. Nazeeruddin, and M. Grätzel, "Analysis of electron transfer properties of $\mathrm{ZnO}$ and $\mathrm{TiO} 2$ photoanodes for dye-sensitized solar cells," ACS Nano, vol. 8, pp. 2261-2268, 2014.
[76] J. A. Anta, E. Guillen, and R. Tena-Zaera, "ZnO-based dyesensitized solar cells," The Journal of Physical Chemistry C, vol. 116, pp. 11413-11425, 2012.

[77] V. Kandavelu, H. Kastien, and K. R. Thampi, "Photocatalytic degradation of iso- thiazolin-3-ones in water and emulsion paints containing nanocrystalline $\mathrm{TiO}_{2}$ and $\mathrm{ZnO}$ catalysts," Applied Catalysis B: Environmental, vol. 48, pp. 101-111, 2004.

[78] M. Mehedi Hassan, A. S. Ahmed, M. Chaman, W. Khan, A. H. Naqvi, and A. Azam, "Structural and frequency dependent dielectric properties of $\mathrm{Fe} 3+$ doped $\mathrm{ZnO}$ nanoparticles," Materials Research Bulletin, vol. 47, no. 12, pp. 3952-3958, 2012.

[79] S. Ambika and M. Sundrarajan, "Antibacterial behaviour of vitex negundo extract assisted $\mathrm{ZnO}$ nanoparticles against pathogenic bacteria," Journal of Photochemistry and Photobiology. B, Biology, vol. 146, pp. 52-57, 2015.

[80] J. Panigrahi, D. Behera, I. Mohanty, U. Subudhi, B. B. Nayak, and B. S. Acharya, "Radio frequency plasma enhanced chemical vapor based $\mathrm{ZnO}$ thin film deposition on glass substrate: a novel approach towards antibacterial agent," Applied Surface Science, vol. 258, pp. 304-311, 2011.

[81] P. Zhu, Z. Weng, X. Li et al., "Biomedical applications of functionalized $\mathrm{ZnO}$ nanomaterials: from biosensors to bioimaging," Advanced Materials Interfaces, vol. 3, no. 1, Article ID 1500494, 2016.

[82] V. Svetlichnyi, A. Shabalina, I. Lapin, D. Goncharova, and A. Nemoykina, "ZnO nanoparticles obtained by pulsed laser ablation and their composite with cotton fabric: preparation and study of antibacterial activity," Applied Surface Science, vol. 372, pp. 20-29, 2016.

[83] N. Güy and M. €Ozacar, "The influence of noble metals on photocatalytic activity of $\mathrm{ZnO}$ for congo red degradation," International Journal of Hydrogen Energy, vol. 41, pp. 20100-20112, 2016.

[84] V. E. Podasca, T. Buruiana, and E. C. Buruiana, "UV-cured polymeric films containing $\mathrm{ZnO}$ and silver nanoparticles with UVevis light-assisted photocatalytic ac- tivity," Applied Surface Science, vol. 377, pp. 262-273, 2016.

[85] K. Shim, M. Abdellatif, E. Choi, and D. Kim, "Nanostructured $\mathrm{ZnO}$ films on stainless steel are highly safe and effective for antimicrobial applications," Applied Microbiology and Biotechnology, vol. 7, pp. 2801-2809, 2017.

[86] G. He, E. I. Pearce, and C. H. Sissons, "Inhibitory effect of $\mathrm{ZnCl}(2)$ on glycolysis in human oral microbes," Archives of Oral Biology, vol. 47, pp. 117-129, 2002.

[87] S. George, S. Pokhrel, T. Xia et al., "Use of a rapid cytotoxicity screening approach to engineer a safer zinc oxide nanoparticle through iron doping," ACS Nano, vol. 4, pp. 15-29, 2010.

[88] V. Kononenko, N. Repar, N. Marušič, B. Drašler, T. Romih, and S. Hočevar, D. Drobne, Comparative in vitro genotoxicity study of $\mathrm{ZnO}$ nanoparticles, $\mathrm{ZnO}$ macroparticles and $\mathrm{ZnCl} 2$ to MDCK kidney cells: size matters," Toxicology in Vitro: An International Journal Published in Association with BIBRA, vol. 40, pp. 256-263, 2017.

[89] S. Hackenberg, A. Scherzed, A. Technau et al., "Cytotoxic, genotoxic and pro-inflammatory effects of zinc oxide nanoparticles in human nasal mucosa cells in vitro," Toxicology in Vitro: An International Journal Published in Association with BIBRA, vol. 25, pp. 657-663, 2011.

[90] C. B. Ong, L. Y. Ng, and A. W. Mohammad, "A review of $\mathrm{ZnO}$ nanoparticles as solar photocatalysts: synthesis, 
mechanisms and applications," Renewable and Sustainable Energy Reviews, vol. 81, pp. 536-551, 2018.

[91] S. Xu and Z. L. Wang, "One-dimensional $\mathrm{ZnO}$ nanostructures: solution growth and functional properties," Nano Research, vol. 4, no. 11, pp. 1013-1098, 2011.

[92] H. Li, X Zhang, N Liu et al., "Enhanced photo-response properties of a single $\mathrm{ZnO}$ microwire photodetector by coupling effect between localized Schottky barriers and piezoelectric potential," Optics Express, vol. 23, pp. 2120421212, 2015.

[93] D. C. Onwudiwe, T. Arfin, and C. A. Strydom, "Surfactant mediated synthesis of $\mathrm{ZnO}$ nanospheres at elevated temperature, and their dielectric properties," Superlattices and Microstructures, vol. 81, pp. 215-225, 2015.

[94] N. Wiesmann, M. Kluenker, P. Demuth, W. Brenner, W. Tremel, and J. Brieger, "Zinc overload mediated by zinc oxide nanoparticles as innovative anti-tumor agent," Journal of Trace Elements in Medicine and Biology, vol. 51, pp. 226-234, 2019.

[95] M. Khatami, R. S. Varma, N. Zafarnia, H. Yaghoobi, M. Sarani, and V. G. Kumar, "Applications of green synthesized $\mathrm{Ag}, \mathrm{ZnO}$ and $\mathrm{Ag} / \mathrm{ZnO}$ nanoparticles for making clinical antimicrobial wound-healing bandages," Sustainable Chemistry and Pharmacy, vol. 10, pp. 9-15, 2018.

[96] A. Król, P. Pomastowski, K. Rafińska, V. Railean-Plugaru, and B. Buszewski, "Zinc oxide nanoparticles: synthesis, antiseptic activity and toxicity mechanism," Advances in Colloid and Interface Science, vol. 249, pp. 37-52, 2017.

[97] J. V. Chandar, S. Shanmugan, D. Mutharasu, and A. A. Aziz, "Dielectric and UV Absorption studies of $\mathrm{ZnO}$ nanoparticles reinforced Polyv (3-hydroxybutyrate) biocomposites for UV," Biopolymer Nanocomposites, vol. 8, pp. 123-128, 2016.

[98] L. Al-Naamani, S. Dobretsov, and J. Dutta, "Chitosan-zinc oxide nanoparticle composite coating for active food packaging applications," Innovative Food Science \& Emerging Technologies, vol. 38, pp. 231-237, 2016.

[99] Y. K. Mishra and R. Adelung, "ZnO tetrapod materials for functional applications," Materials Today, vol. 21, no. 6, pp. 631-651, 2018.

[100] X. Gu, T. Qiu, W. Zhang, and P. K. Chu, "Light-emitting diodes enhanced by localized surface plasmon resonance," Nanoscale Research Letters, vol. 6, no. 1, pp. 199-212, 2011.

[101] P. Uthirakumar, Y.-S. Lee, E.-K. Suh, and C.-H. Hong, "Hybrid fluorescent polymer-zinc oxide nanoparticles: improved efficiency for luminescence conversion LED," Journal of Luminescence, vol. 128, no. 3, pp. 287-296, 2008.

[102] A. Kolodziejczak-Radzimska and T. Jesionowski, "Zinc oxide-from synthesis to application: a review," Materials (Basel).vol. 7, pp. 2833-2881, 2014.

[103] J. McKittrick et al., "Phosphor selection considerations for near-UV LED solid state lighting," ECS Journal of Solid State Science and Technology, vol. 2, pp. 3119-3131, 2013.

[104] B. Karthikeyan, T. Pandiyarajan, and R. V. Mangalaraja, "Enhanced blue light emission in transparent ZnO:PVA nanocomposite free standing polymer films," Spectrochimica Acta Part A: Molecular and Biomolecular Spectroscopy, vol. 152, pp. 485-490, 2016.

[105] F. H. Alshammari, P. K. Nayak, Z. Wang, and H. N. Alshareef, "Enhanced $\mathrm{ZnO}$ thin-film transistor performance using bilayer gate dielectrics," ACS Applied Materials \& Interfaces, vol. 8, no. 35, pp. 22751-22755, 2016.

[106] J.-S. Park, H. Kim, and I.-D. Kim, "Overview of electroceramic materials for oxide semiconductor thin film transistors," Journal of Electroceramics, vol. 32, no. 2-3, pp. 117-140, 2014.

[107] S. Lee, H. Kim, D. J. Yun, S. W. Rhee, and K. Yong, "Resistive switching characteristics of $\mathrm{ZnO}$ thin film grown on stainless steel for flexible nonvolatile memory devices," Applied Physics Letters, vol. 95, pp. 13-16, 2009.

[108] Z. Zang, "Efficiency enhancement of $\mathrm{ZnO} / \mathrm{Cu}_{2} \mathrm{O}$ solar cells with well oriented and micrometer grain sized $\mathrm{Cu}_{2} \mathrm{O}$ films," Applied Physics Letters, vol. 112, 2018.

[109] K. Qi, B. Cheng, J. Yu, and W. Ho, "Review on the improvement of the photocatalytic and antibacterial activities of ZnO," Journal of Alloys and Compounds, vol. 727, pp. 792-820, 2017.

[110] M. A. Basyooni, M. Shaban, and A. M. El Sayed, "Enhanced gas sensing properties of spin-coated Na-doped $\mathrm{ZnO}$ nanostructured films," Scientific Reports, vol. 7, pp. 4171641812, 2017.

[111] C. Li, Z. Zang, C. Han et al., "Highly compact CsPbBr3 perovskite thin films decorated by $\mathrm{ZnO}$ nanoparticles for enhanced random lasing," Nano Energy, vol. 40, pp. 195-202, 2017.

[112] M. Laurenti, N. Garino, S. Porro, M. Fontana, and C. Gerbaldi, "Zinc oxide nanostructures by chemical vapour deposition as anodes for Li-ion batteries," Journal of Alloys and Compounds, vol. 640, pp. 321-326, 2015.

[113] C. Li, C. Han, Y. Zhang et al., "Enhanced photoresponse of self-powered perovskite photodetector based on $\mathrm{ZnO}$ nanoparticles decorated $\mathrm{CsPbBr} 3$ films," Solar Energy Materials and Solar Cells, vol. 172, pp. 341-346, 2017.

[114] S. Adachi, Handbook on Physical Properties of Semiconductor, Springer, New York, NY, USA, 2004.

[115] D. C. Look, D. C. Reynolds, J. R. Sizelove et al., "Electrical properties of bulk ZnO," Solid State Communications, vol. 105 , no. 6 , pp. $399-401,1998$.

[116] N. H. Langton and D. Matthews, "The dielectric constant of zinc oxide over a range of frequencies," British Journal of Applied Physics, vol. 9, no. 11, pp. 453-456, 1958.

[117] S. Sharma, C. Periasamy, and P. Chakrabarti, "Thickness dependent study of RF sputtered $\mathrm{ZnO}$ thin films for optoelectronic device applications," Electronic Materials Letters, vol. 11, no. 6, pp. 1093-1101, 2015.

[118] X. D. Li et al., "A study on the evolution of dielectric function of $\mathrm{ZnO}$ thin films with decreasing film thickness," Journal of Applied Physics, vol. 115, pp. 1-6, 2014.

[119] D. Pal, J. Singhal, A. Mathur et al., "Effect of substrates and thickness on optical properties in atomic layer deposition grown $\mathrm{ZnO}$ thin films," Applied Surface Science, vol. 421, pp. 341-348, 2017.

[120] M. L. Dinesha, G. D. Prasanna, C. S. Naveen, and H. S. Jayanna, "Structural and dielectric properties of Fe doped $\mathrm{ZnO}$ nanoparticles," Indian Journal of Physics, vol. 87, no. 2 , pp. 147-153, 2013.

[121] M. Mehedi Hassan, W. Khan, A. Azam, and A. H. Naqvi, "Influence of $\mathrm{Cr}$ incorporation on structural, dielectric and optical properties of $\mathrm{ZnO}$ nanoparticles," Journal of Industrial and Engineering Chemistry, vol. 21, pp. 283-291, 2015.

[122] M. N. Siddique, T. Ali, A. Ahmed, and P. Tripathi, "Enhanced electrical and thermal properties of pure and $\mathrm{Ni}$ substituted ZnO Nanoparticles," Nano-Structures \& NanoObjects, vol. 16, pp. 156-166, 2018.

[123] J. Iqbal, N. Safdar, T. Jan et al., "Facile synthesis as well as structural, Raman, dielectric and antibacterial characteristics of $\mathrm{Cu}$ doped $\mathrm{ZnO}$ nanoparticles," Journal of Materials Science \& Technology, vol. 31, no. 3, pp. 300-304, 2015. 
[124] S. Suresh, "Studies on the dielectric properties of CdS nanoparticles," Applied Nanoscience, vol. 4, no. 3, pp. 325-329, 2014.

[125] T. A. Safeera and E. I. Anila, "Wet chemical synthesis of chitosan capped $\mathrm{ZnO}: \mathrm{Na}$ nanoparticles for luminescence applications," International Journal of Biological Macromolecules, vol. 104, pp. 1833-1836, 2017.

[126] K. Sato and H. Katayama-Yoshida, "Material design for transparent ferromagnets with $\mathrm{ZnO}$-based magnetic semiconductors," Japanese Journal of Applied Physics, vol. 39, 2000 .

[127] J. Neamtu and M. Volmer, "The influence of doping with transition metal ions on the structure and magnetic properties of zinc oxide thin films," The Scientific World Journal, vol. 20147 pages, 2014.

[128] S. Singh, J. N. D. Deepthi, B. Ramachandran, and M. S. R. Rao, "Synthesis and comparative study of Ho and y doped ZnO nanoparticles," Materials Letters, vol. 65, no. 1920, pp. 2930-2933, 2011.

[129] S. Das, S. Das, and S. Sutradhar, "Effect of Gd 3+ and Al 3+ on optical and dielectric properties of $\mathrm{ZnO}$ nanoparticle prepared by two-step hydrothermal method," Ceramics International, vol. 43, no. 9, pp. 6932-6941, 2017.

[130] A. Franco Jr and H. V. S. Pessoni, "Effect of Gd doping on the structural, optical band-gap, dielectric and magnetic properties of ZnO nanoparticles," Physica B: Condensed Matter, vol. 506, pp. 145-151, 2017.

[131] S. A. Ansari, A. Nisar, B. Fatma, W. Khan, and A. H. Naqvi, "Investigation on structural, optical and dielectric properties of $\mathrm{Co}$ doped $\mathrm{ZnO}$ nanoparticles synthesized by gel-combustion route," Materials Science and Engineering: $B$, vol. 177, no. 5, pp. 428-435, 2012.

[132] A. F. Jr and H. V. S. Pessoni, "Enhanced dielectric constant of Co-doped $\mathrm{ZnO}$ nanoparticulate powders," Physica B: Condensed Matter, vol. 476, pp. 12-18, 2015.

[133] S. O. Kasap, Principles of Electronic Materials and Devices, McGraw Hill Education, New York, NY, USA, 2001.

[134] J. Maxwell, “A treatise on electricity and magnetism," 1873.

[135] C. G. Koops, "On the dispersion of resistivity and dielectric constant of some semiconductors at audiofrequencies," Physical Review, vol. 83, no. 1, pp. 121-124, 1951.

[136] K. W. . Wagner, "Zur theorie der unvollkommenen dielektrika," Annalen der Physik, vol. 345, no. 5, 1913.

[137] Z. Bin, Z. Shaomin, W. Haiwei, and D. Zuliang, "Raman scattering and photoluminescence of Fe-doped $\mathrm{ZnO}$ nanocantilever arrays," Science Bulletin, vol. 53, no. 11, pp. 1639-1643, 2008.

[138] H. Liu, J. Yang, Y. Zhang, L. Yang, M. Wei, and X. Ding, "Structure and magnetic properties of Fe-doped $\mathrm{ZnO}$ prepared by the sol-gel method," Condensed Matter, vol. 10, 2009.

[139] B. Rajesh Kumar, B. Hymavathi, and T. Subba Rao, "Effect of the ceria dopant on the structural and dielectric properties of $\mathrm{ZnO}$ semiconductors," Journal of Science: Advanced Materials and Devices, vol. 3, no. 4, pp. 433-439, 2018.

[140] S. Goel, N. Sinha, H. Yadav, S. Godara, A. J. Joseph, and B. Kumar, "Ferroelectric Gd-doped $\mathrm{ZnO}$ nanostructures: enhanced dielectric, ferroelectric and piezoelectric properties," Materials Chemistry and Physics, vol. 202, pp. 56-64, 2017.

[141] S. Goel, N. Sinha, H. Yadav, A. J. Joseph, and B. Kumar, "Experimental investigation on the structural, dielectric, ferroelectric and piezoelectric properties of $\mathrm{La}$ doped $\mathrm{ZnO}$ nanoparticles and their application in dye-sensitized solar cells," Physica E: Low-Dimensional Systems and Nanostructures, vol. 91, pp. 72-81, 2017.

[142] N. K. Divya and P. P. Pradyumnan, "Enhancement of photocatalytic activity in $\mathrm{Nd}$ doped $\mathrm{ZnO}$ with an increase in dielectric constant," Journal of Materials Science: Materials in Electronics, vol. 28, no. 2, pp. 2147-2156, 2017.

[143] A. Franco and H. V. Pessoni, "Optical band-gap and dielectric behavior in Ho -doped $\mathrm{ZnO}$ nanoparticles," Materials Letters, vol. 180, pp. 305-308, 2016.

[144] R. Zamiri, A. Kaushal, A. Rebelo, and J. M. F. Ferreira, "Er doped $\mathrm{ZnO}$ nanoplates: synthesis, optical and dielectric properties," Ceramics International, vol. 40, no. 1, pp. 1635-1639, 2014.

[145] A. Bandyopadhyay, N. Bhakta, S. Sutradhar et al., "Microstructure investigation, optical properties and magnetic phase transition of $\mathrm{Tm} 3+$ substituted nanocrystalline $\mathrm{ZnO}$ (Zn0.95Tm0.05O)," RSC Advances, vol. 6, no. 104, pp. 101818-101826, 2016.

[146] T. Tanaka, G. C. Montanari, and R. Mulhaupt, "Polymer nanocomposites as dielectrics and electrical insulationperspectives for processing technologies," Material Characterization and Future Applications, vol. 11, no. 5, 2004.

[147] M. F. Frechette, M. L. Trudeau, H. D. Alamdari, and S. Boily, "Introductory remarks on nanodielectrics," IEEE Transactions on Dielectrics and Electrical Insulation, vol. 11, no. 5, pp. 808-818, 2004.

[148] M. Kozako, N. Fuse, Y. Ohki, T. Okamoto, and T. Tanaka, "Surface degradation of polyamide nanocomposites caused by partial discharges using IEC (b) electrodes," IEEE Transactions on Dielectrics and Electrical Insulation, vol. 11, no. 5, pp. 833-839, 2004.

[149] W. Peukert, H.-C. Schwarzer, M. Götzinger, L. Günther, and F. Stenger, "Control of particle interfaces - the critical issue in nanoparticle technology," Advanced Powder Technology, vol. 14, no. 4, pp. 411-426, 2003.

[150] B. J. Ash, R. W. Siegel, and L. S. Schadler, "Glass-transition temperature behavior of alumina/PMMA nanocomposites," Journal of Polymer Science Part B: Polymer Physics, vol. 42, no. 23, pp. 4371-4383, 2004.

[151] B. J. Ash et al., "Mechanical properties of AI , O ,! polymethylmethacrylate nanocomposites," Polymer Composites, vol. 23, 2002.

[152] Z.-M. Dang, L.-Z. Fan, S.-J. Zhao, and C.-W. Nan, "Preparation of nanosized $\mathrm{ZnO}$ and dielectric properties of composites filled with nanosized $\mathrm{ZnO}$," Materials Science and Engineering: B, vol. 99, no. 1-3, pp. 386-389, 2003.

[153] M. Samet, V Levchenko, G Boiteux, G Seytre, A Kallel, and A Serghei, "Electrode polarization vs. Maxwell-Wagner-Sillars interfacial polarization in dielectric spectra of materials: characteristic frequencies and scaling laws," The Journal of Chemical Physics, vol. 142, Article ID 194703, 2015.

[154] S. A. Mansour, R. A. Elsad, and M. A. Izzularab, "Dielectric properties enhancement of PVC nanodielectrics based on synthesized $\mathrm{ZnO}$ nanoparticles," Journal of Polymer Research, vol. 23, 2016.

[155] S. Choudhary, "Structural, optical, dielectric and electrical properties of (PEO-PVP)-ZnO nanocomposites," Journal of Physics and Chemistry of Solids, vol. 121, pp. 196-209, 2018.

[156] J. I. Hong, P. Winberg, L. S. Schadler, and R. W. Siegel, "Dielectric properties of zinc oxide/low density polyethylene nanocomposites," Materials Letters, vol. 59, no. 4, pp. 473-476, 2005.

[157] A. Mahmood, A. Naeem, A. Mahmood, and A. Naeem, "High- $K$ polymer nanocomposites nanocomposites for for 
energy energy storage storage applications," Properties and Applications of Polymer Dielectrics, vol. 90, 2017.

[158] C.-C. Shih, W.-Y. Lee, Y.-C. Chiu et al., "High performance transparent transistor memory devices using nano-floating gate of polymer/ZnO nanocomposites," Scientific Reports, vol. 6, no. 1, p. 10, 2016.

[159] Z. A. Kösemen, A. Kösemen, S. Öztürk et al., "Effect of intrinsic polymer properties on the photo sensitive organic field-effect transistors (Photo-OFETs)," Microelectronic Engineering, vol. 161, pp. 36-42, 2016.

[160] S. Bi, Y. Li, Z. He, Z. Ouyang, Q. Guo, and C. Jiang, "Selfassembly diketopyrrolopyrrole-based materials and polymer blend with enhanced crystal alignment and property for organic field-effect transistors," Organic Electronics, vol. 65, pp. 96-99, 2019.

[161] B. B. Patowary, S. Laskar, P. P. Sahu, and R. Narzary, "Fabrication and electrical characterization of organic fieldeffect transistor based on CSA doped PANi-Ta 2 O 5 nanocomposite," ADBU Journal of Engineering Technology (AJET), vol. 9, pp. 1-8, 2020.

[162] S. Cichosz, A. Masek, and M. Zaborski, "Polymer-based sensors: a review," Polymer Testing, vol. 67, pp. 342-348, 2018.

[163] Z. Xiao, L. B. Kong, S. Ruan et al., "Recent development in nanocarbon materials for gas sensor applications," Sensors and Actuators B: Chemical, vol. 274, pp. 235-267, 2018.

[164] R. Megha, F. A. Ali, Y. T. Ravikiran et al., "Conducting polymer nanocomposite based temperature sensors: a review," Inorganic Chemistry Communications, vol. 98, pp. 11-28, 2018.

[165] A. Jafari and A. Amini, "Lactic acid gas sensor based on polypyrrole thin film," Materials Letters, vol. 236, pp. 175178, 2019.

[166] A. Husain, M. U. Shariq, and F. Mohammad, "DC electrical conductivity and liquefied petroleum gas sensing application of polythiophene/zinc oxide nanocomposite," Materialia, vol. 9, Article ID 100599, 2020.

[167] L. Lan, P. Cai, Y. Mai et al., "A new wide-bandgap conjugated polymer based on imide-fused benzotriazole for highly efficient nonfullerene polymer solar cells," Dyes and Pigments, vol. 158, pp. 219-224, 2018.

[168] F. Arabpour Roghabadi, N. Ahmadi, V. Ahmadi et al., "Bulk heterojunction polymer solar cell and perovskite solar cell: concepts, materials, current status, and opto-electronic properties," Solar Energy, vol. 173, pp. 407-424, 2018.

[169] G. Li et al., "A new narrow bandgap polymer as donor material for high performance non- fullerene polymer solar cells," Organic Electronics, vol. 64, pp. 241-246, 2018.

[170] G. Sai-Anand, A. Dubey, A.-I. Gopalan et al., "Additive assisted morphological optimization of photoactive layer in polymer solar cells," Solar Energy Materials and Solar Cells, vol. 182, pp. 246-254, 2018.

[171] M. Naskar, H. M. Dharmendra, and G. L. Sarode, "Preparation and properties of nano zinc oxide doped ethylene vinyl acetate nanocomposites for solar cell encapsulation," Materials Today: Proceedings, vol. 27, pp. 1939-1942, 2019.

[172] M. Yoke, "Enhancing the performance of green solid-state electric double-layer capacitor incorporated with fumed silica nanoparticles," Journal of Physics and Chemistry of Solids, vol. 117, pp. 194-203, 2018.

[173] Z. Pan, L. Yao, J. Zhai, X. Yao, and H. Chen, "Interfacial coupling effect in organic/inorganic nanocomposites with high energy density," Advanced Materials, vol. 2, pp. 1-7, 2018.
[174] D. Zhang, Z. Wu, X.-f. Zhou, A.-q. Wei, C. Chen, and H. Luo, "High energy density in $\mathrm{P}(\mathrm{VDF}-\mathrm{HFP})$ nanocomposite with paraffin engineered BaTiO3 nanoparticles," Sensors and Actuators A: Physical, vol. 260, pp. 228-235, 2017.

[175] J. Chen, X. Wang, X. Yu et al., "High dielectric constant and low dielectric loss poly(vinylidene fluoride) nanocomposites via a small loading of two-dimensional $\mathrm{Bi}_{2} \mathrm{Te}_{3} @ \mathrm{Al}_{2} \mathrm{O}_{3}$ hexagonal nanoplates," Journal of Materials Chemistry C, vol. 6, no. 2, pp. 271-279, 2018.

[176] P. Arunachalam, "Polymer-based nanocomposites for energy and environmental applications," Polymer-based Nanocomposites for Energy and Environmental Applications, vol. 30, pp. 185-203, 2018.

[177] S. Chakraborty, M. Amla, and A. R. Mary, "Biocompatible supercapacitor electrodes using green synthesised $\mathrm{ZnO} /$ Polymer nanocomposites for efficient energy storage applications," Journal of Energy Storage, vol. 28, Article ID $101275,2020$.

[178] A. Shayesteh Zeraati and U. Sundararaj, "Carbon nanotube/ $\mathrm{ZnO}$ nanowire/polyvinylidene fluoride hybrid nanocomposites for enhanced electromagnetic interference shielding," The Canadian Journal of Chemical Engineering, vol. 98, no. 5, pp. 1036-1046, 2020.

[179] S. Zhang, G. Sun, Y. He, R. Fu, Y. Gu, and S. Chen, "Preparation, characterization, and electrochromic properties of nanocellulose-based polyaniline nanocomposite films," ACS Applied Materials \& Interfaces, vol. 9, no. 19, pp. 16426-16434, 2017.

[180] F. Xu, H. Zhang, L. Jin et al., "Controllably degradable transient electronic antennas based on water-soluble PVA/ $\mathrm{TiO}_{2}$ films," Journal of Materials Science, vol. 53, no. 4, pp. 2638-2647, 2018.

[181] M. Belhaj, C. Dridi, H. Elhouichet, and J. C. Valmalette, "Study of $\mathrm{ZnO}$ nanoparticles based hybrid nanocomposites for optoelectronic applications," Journal of Applied Physics, vol. 119, 2016.

[182] H. Zhang, X. Zhao, J. Huang et al., "Bistable non-volatile resistive memory devices based on $\mathrm{ZnO}$ nanoparticles embedded in polyvinylpyrrolidone," RSC Advances, vol. 10, no. 25 , pp. $14662-14669,2020$.

[183] E. Helal, C. Pottier, E. David, M. Fréchette, and N. R. Demarquette, "Polyethylene/thermoplastic elastomer/ Zinc Oxide nanocomposites for high voltage insulation applications: dielectric, mechanical and rheological behavior," European Polymer Journal, vol. 100, pp. 258-269, 2018.

[184] D. Ponnamma, J.-J. Cabibihan, M. Rajan et al., "Synthesis, optimization and applications of $\mathrm{ZnO} /$ polymer nanocomposites," Materials Science and Engineering: C, vol. 98, pp. 1210-1240, 2019.

[185] J. Anandraj and G. M. Joshi, "Fabrication, performance and applications of integrated nanodielectric properties of materials - a review," Composite Interfaces, vol. 25, no. 5-7, pp. 455-489, 2018.

[186] S. Choudhary, "Characterization of amorphous silica nanofiller effect on the structural, morphological, optical, thermal, dielectric and electrical properties of PVA-PVP blend based polymer nanocomposites for their flexible nanodielectric applications," Journal of Materials Science: Materials in Electronics, vol. 29, no. 12, pp. 10517-10534, 2018.

[187] A. Geczy, T. Garami, B. Kovacs et al., "Soldering tests with biodegradable printed circuit boards," in Proceedings of the 2013 IEEE 19th International Symposium for Design and 
Technology in Electronic Packaging (SIITME), pp. 39-42, Galati, Romania, October 2013.

[188] A. Geczy, M. Kovacs, and I. Hajdu, "Conductive layer deposition and peel tests on biodegradable printed circuit boards," in Proceedings of the 2012 IEEE 18th International Symposium for Design and Technology in Electronic Packaging (SITTME), pp. 139-142, Alba Iulia, Romania, October 2012.

[189] P. Nayak, S. Kumar, I. Sinha, and K. K. Singh, “ZnO/CuO nanocomposites from recycled printed circuit board: preparation and photocatalytic properties," Environmental Science and Pollution Research, vol. 26, no. 16, pp. 1627916288, 2019.

[190] V. C. Janakiraman, S. Subramani, M. Devarajan, and A. Abdul Aziz, "Impact of $\mathrm{ZnO}$ nanoparticles on dielectric and optical properties of poly (3-hydroxybutyrate) for electronics applications," Polymer-Plastics Technology and Engineering, vol. 56, no. 14, pp. 1495-1504, 2017.

[191] A. Bashir, S. Jabeen, N. Gull et al., "Co-concentration effect of silane with natural extract on biodegradable polymeric films for food packaging," International Journal of Biological Macromolecules, vol. 106, pp. 351-359, 2018.

[192] Y. Zhong, P. Godwin, Y. Jin, and H. Xiao, "Biodegradable polymers and green-based antimicrobial packaging materials: a mini-review," Advanced Industrial and Engineering Polymer Research, vol. 3, no. 1, pp. 27-35, 2020.

[193] M. Ramesh, G. Narendra, and S. Sasikanth, A Review on Biodegradable Packaging Materials in Extending the Shelf Life and Quality of Fresh Fruits and Vegetables .Waste Management As Economic Industry towards Circular Economy, Springer, Singapore, Singapore, 2020.

[194] S. K. Fanourakis, J. Peña-Bahamonde, P. C. Bandara, and D. F. Rodrigues, "Nano-based adsorbent and photocatalyst use for pharmaceutical contaminant removal during indirect potable water reuse," Npj Clean Water, vol. 3, 2020.

[195] R. Mukhopadhyay, D. Bhaduri, B. Sarkar et al., "Claypolymer nanocomposites: progress and challenges for use in sustainable water treatment," Journal of Hazardous Materials, vol. 383, Article ID 121125, 2020.

[196] J. Karlsson, H. J. Vaughan, and J. J. Green, "Biodegradable polymeric nanoparticles for therapeutic cancer treatments," Annual Review of Chemical and Biomolecular Engineering, vol. 9, no. 1, pp. 105-127, 2018.

[197] X. Montané et al., "Encapsulation for cancer therapy," Molecules, vol. 25, pp. 1-25, 2020.

[198] M. Alsehli, "Polymeric nanocarriers as stimuli-responsive systems for targeted tumor (cancer) therapy: recent advances in drug delivery," Saudi Pharmaceutical Journal, vol. 28, no. 3, pp. 255-265, 2020.

[199] P. Sharma, P. Negi, and N. Mahindroo, "Recent advances in polymeric drug delivery carrier systems," Advanced Polymer Biomedical Applications, vol. 10, pp. 369-388, 2018.

[200] E. Calzoni, A Cesaretti, A Polchi, A Di Michele, B Tancini, and C Emiliani, "Biocompatible polymer nanoparticles for drug delivery applications in cancer and neurodegenerative disorder therapies," Journal of Functional Biomaterials, vol. 10, no. 1, pp. 1-15, 2019.

[201] W. Mu, Q. Chu, Y. Liu, and N. Zhang, "A review on nanobased drug delivery system for cancer chemoimmunotherapy," Nano-Micro Letter, vol. 12, 2020.

[202] R. Ghosh, M. Malhotra, R. R. M. Sathe, and M. Jayakannan, "Biodegradable polymer theranostic fluorescent nanoprobe for direct visualization and quantitative determination of antimicrobial activity," Biomacromolecules, vol. 21, no. 7, pp. 2896-2912, 2020.

[203] J. A. Da Cruz, A. B. da Silva, B. B. S. Ramin et al., "Poly(vinyl alcohol)/cationic tannin blend films with antioxidant and antimicrobial activities," Materials Science and Engineering: C, vol. 107, Article ID 110357, 2020.

[204] X. Peng, K Dong, C Ye et al., "A breathable, biodegradable, antibacterial, and self-powered electronic skin based on allnanofiber triboelectric nanogenerators," Science Advances, vol. 6, p. 9624, 2020.

[205] M. Silva, F. N. Ferreira, N. M. Alves, and M. C. Paiva, "Biodegradable polymer nanocomposites for ligament/tendon tissue engineering," Journal of Nanobiotechnology, vol. 18, pp. 23-33, 2020.

[206] M. Milkoreit, "Wireless implantable and biodegradable sensors for postsurgery monitoring: current status and future perspectives Ac ce pte d M us pt," Geophysical Research Letters, vol. 99, pp. 10-31. in Press, 2017.

[207] G. Yang, J. Zhao, S. Yi, X. Wan, and J. Tang, "Biodegradable and photostable $\mathrm{Nb} 2 \mathrm{C}$ MXene quantum dots as promising nanofluorophores for metal ions sensing and fluorescence imaging," Sensors and Actuators B: Chemical, vol. 309, Article ID 127735, 2020.

[208] A. Sukan, I. Roy, and T. Keshavarz, "Agro-industrial waste materials as substrates for the production of poly(3hydroxybutyric acid)," Journal of Biomaterials and Nanobiotechnology, vol. 5, no. 4, pp. 229-240, 2014.

[209] Ł. Kaniuk, Z. J. Krysiak, S. Metwally, and U. Stachewicz, "Osteoblasts and fibroblasts attachment to poly(3-hydroxybutyric acid-co-3-hydrovaleric acid) (PHBV) film and electrospun scaffolds," Materials Science \& Engineering. C, Materials for Biological Applications, vol. 110, Article ID 110668, 2020.

[210] H. Brandl, R. A. Gross, R. W. Lenz, and R. C. Fuller, "Plastics from bacteria and for bacteria: poly(beta-hydroxyalkanoates) as natural, biocompatible, and biodegradable polyesters," Advances in Biochemical Engineering/biotechnology, vol. 41, pp. 77-93, 1990.

[211] A. Steinbüchel, "Polyhydroxyalkanoic acids," Biomaterials, vol. 40, pp. 123-213, 1991.

[212] D. Jendrossek, A. Schirmer, and H. G. Schlegel, "Biodegradation of polyhydroxyalkanoic acids," Applied Microbiology and Biotechnology, vol. 46, no. 5-6, pp. 451-463, 1996.

[213] N. Stephen, Lighting and UV radiation: where do LEDs fit in? http://www.leapfroglighting.com/lighting_and_uv_radi ation/, 2012.

[214] A. Becheri, M. Dürr, P. Lo Nostro, and P. Baglioni, "Synthesis and characterization of zinc oxide nanoparticles: application to textiles as UV-absorbers," Journal of Nanoparticle Research, vol. 10, no. 4, pp. 679-689, 2008.

[215] R. Wang, J. H. Xin, X. M. Tao, and W. A. Daoud, "ZnO nanorods grown on cotton fabrics at low temperature," Chemical Physics Letters, vol. 398, no. 1-3, pp. 250-255, 2004.

[216] I. Shahid-Ul, M. Shahid, and F. Mohammad, "Green chemistry approaches to develop antimicrobial textiles based on sustainable biopolymers-a review," Industrial \& Engineering Chemistry Research, vol. 52, no. 15, pp. 5245-5260, 2013.

[217] C. Shuai et al., "Enhanced crystallinity and antibacterial of PHBV scaffolds incorporated with zinc oxide," Journal of Nanomaterials, vol. 2020, Article ID 6014816, 12 pages, 2020.

[218] J. L. Castro-Mayorga, M. J. Fabra, A. M. Pourrahimi, R. T. Olsson, and J. M. Lagaron, "The impact of zinc oxide particle morphology as an antimicrobial and when 
incorporated in poly(3-hydroxybutyrate-co-3-hydroxyvalerate) films for food packaging and food contact surfaces applications," Food and Bioproducts Processing, vol. 101, pp. 32-44, 2017.

[219] K. J. Figueroa-Lopez, "lectrospun active biopapers of food waste derived poly (3- hydroxybutyrate-co-3-hydroxyvalerate) with short-term and long-term antimicrobial performance," Nanomaterials, vol. 10, pp. 1-26, 2020.

[220] M. Zare, K. Namratha, S. Ilyas, A. Hezam, S. Mathur, and K. Byrappa, "Smart fortified PHBV-CS biopolymer with $\mathrm{ZnO}$-Ag nanocomposites for enhanced shelf life of food packaging," ACS Applied Materials \& Interfaces, vol. 11, no. 51, pp. 48309-48320, 2019.

[221] R. Tarrahi, Z. Fathi, M. Ö. Seydibeyoğlu, E. Doustkhah, and A. Khataee, "Polyhydroxyalkanoates (PHA): from production to nanoarchitecture," International Journal of Biological Macromolecules, vol. 146, pp. 596-619, 2020.

[222] S. Kashi, R. K. Gupta, T. Baum, N. Kao, and S. N. Bhattacharya, "Dielectric properties and electromagnetic interference shielding effectiveness of graphene-based biodegradable nanocomposites," Materials \& Design, vol. 109, pp. 68-78, 2016.

[223] S. Kashi, R. K. Gupta, S. N. Bhattacharya, and R. J. Varley, "Experimental and simulation study of effect of thickness on performance of (butylene adipate-co-terephthalate) and poly lactide nanocomposites incorporated with graphene as stand-alone electromagnetic interference shielding and metal-backed microwave absorbers," Composites Science and Technology, vol. 195, Article ID 108186, 2020.

[224] R. Sharma, S. M. Jafari, and S. Sharma, "Antimicrobial bionanocomposites and their potential applications in food packaging," Food Control, vol. 112, Article ID 107086, 2020.

[225] P. Mujeeb Rahman, V. M. Abdul Mujeeb, K. Muraleedharan, and S. K. Thomas, "Chitosan/nano $\mathrm{ZnO}$ composite films: enhanced mechanical, antimicrobial and dielectric properties," Arabian Journal of Chemistry, vol. 11, no. 1, pp. 120-127, 2018.

[226] S. Yadav, G. K. Mehrotra, and P. K. Dutta, "Chitosan based $\mathrm{ZnO}$ nanoparticles loaded gallic-acid films for active food packaging," Food Chemistry, vol. 334, Article ID 127605, 2021.

[227] S. Kumar, A. Mudai, B. Roy, I. B. Basumatary, A. Mukherjee, and J. Dutta, "Biodegradable hybrid nanocomposite of chitosan/gelatin and green synthesized zinc oxide nanoparticles for food packaging," Foods, vol. 9, no. 9, p. 1143, 2020.

[228] K. Pandiselvi and S. Thambidurai, "Chitosan-ZnO/polyaniline ternary nanocomposite for high-performance supercapacitor," Ionics, vol. 20, no. 4, pp. 551-561, 2014.

[229] H. El Knidri, R. Belaabed, A. Addaou, A. Laajeb, and A. Lahsini, "Extraction, chemical modification and characterization of chitin and chitosan," International Journal of Biological Macromolecules, vol. 120, pp. 1181-1189, 2018.

[230] O. Boura-Theodoridou, A. Giannakas, P. Katapodis, H. Stamatis, A. Ladavos, and N.-M. Barkoula, "Performance of $\mathrm{ZnO} /$ chitosan nanocomposite films for antimicrobial packaging applications as a function of $\mathrm{NaOH}$ treatment and glycerol/PVOH blending," Food Packaging and Shelf Life, vol. 23, Article ID 100456, 2020.

[231] R. Zhong, Q. Zhong, M. Huo, B. Yang, and H. Li, "Preparation of biocompatible nano- $\mathrm{ZnO} /$ chitosan microspheres with multi-functions of antibacterial, UV-shielding and dye photodegradation," International Journal of Biological Macromolecules, vol. 146, pp. 939-945, 2020.
[232] S. Kumar, B. Krishnakumar, A. J. F. N. Sobral, and J. Koh, "Bio-based (chitosan/PVA/ZnO) nanocomposites film: thermally stable and photoluminescence material for removal of organic dye," Carbohydrate Polymers, vol. 205, pp. 559-564, 2019.

[233] S.-B. Ghaffari, M.-H. Sarrafzadeh, M. Salami, and M. R. Khorramizadeh, "A pH-sensitive delivery system based on $\mathrm{N}$-succinyl chitosan- $\mathrm{ZnO}$ nanoparticles for improving antibacterial and anticancer activities of curcumin," International Journal of Biological Macromolecules, vol. 151, pp. 428-440, 2020. 